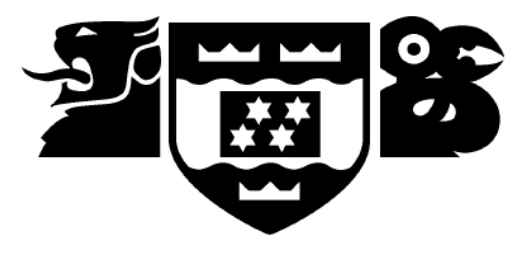

\title{
AN EXAMINATION OF YOUNG WOMEN'S USE OF CONDOMS IN CASUAL SEX SITUATIONS: IMPLICATIONS FOR THE SEXUALITY EDUCATION CURRICULUM.
}

BY

\section{ANNETTE COOPER}

A thesis presented in fulfilment of the requirements of the degree of Master of Arts (M.A)

Victoria University of Wellington, Wellington, New Zealand 


\section{Table of Contents}

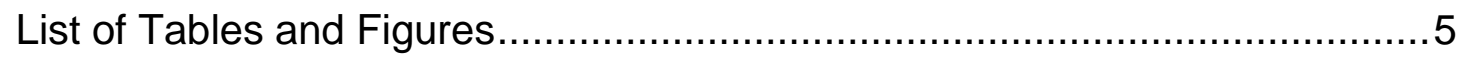

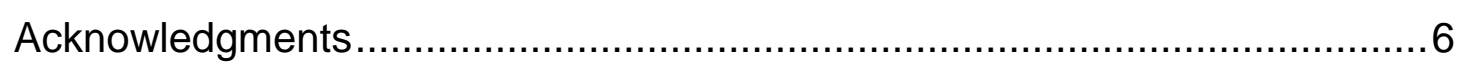

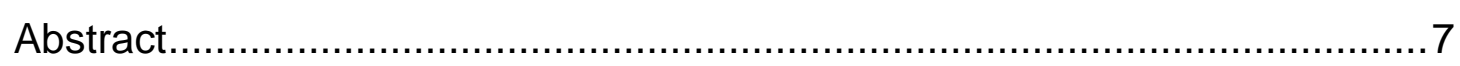

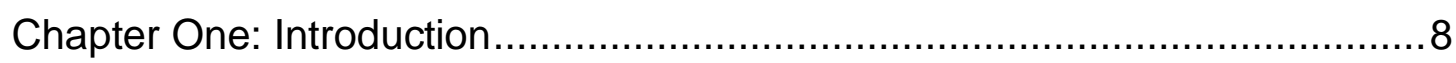

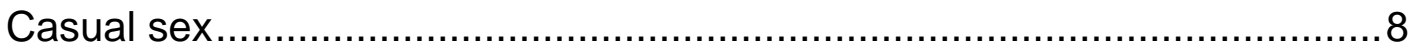

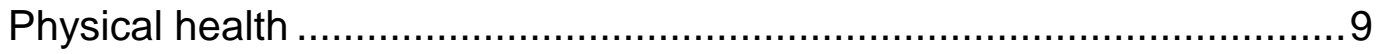

Mental Health ............................................................................ 10

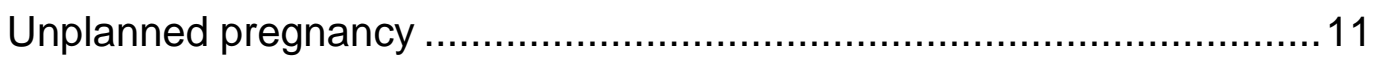

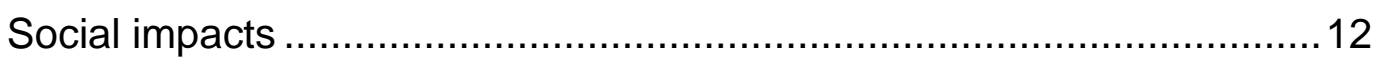

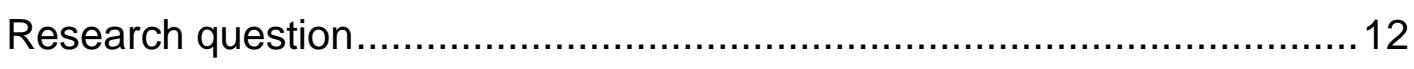

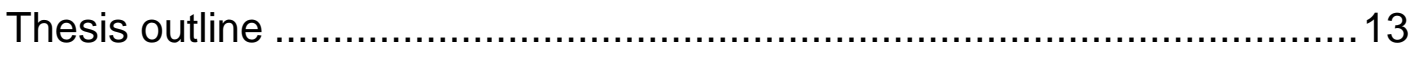

Chapter Two: Adolescence and sex ................................................ 15

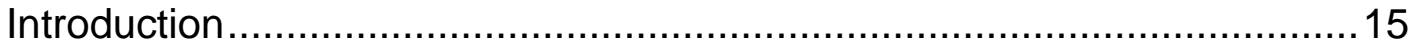

The development of a sexual identity for young women .......................... 15

The influence of Religion ....................................................... 19

The developing brain and risk taking .............................................. 19

The Developing Brain and Alcohol ...............................................22

Young People, Relationships and Sex ............................................ 23

Alcohol/drugs and Unprotected Sex ............................................ 24

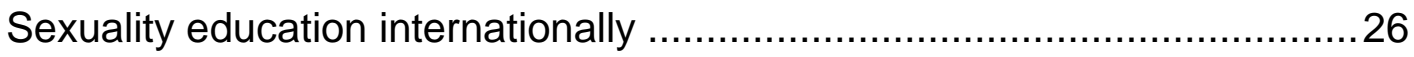

Abstinence only programmes ................................................ 28

Sexuality Education in New Zealand ............................................29

Creating a structure for behaviour change - theoretical models................ 37

Transtheoretical Stages of Change ................................................ 37

The Health Belief Model ....................................................... 38

Social Cognitive Theory ............................................................... 39

Behaviour change in action: Uganda and HIV/AIDS ............................40

Behaviours that reduce STIs and unwanted pregnancy ........................ 41

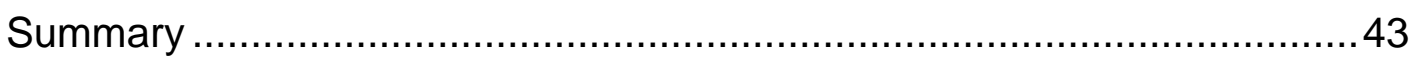

Chapter Three: Research Approach and Methods................................... 45 


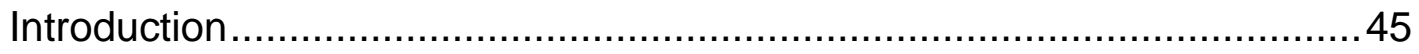

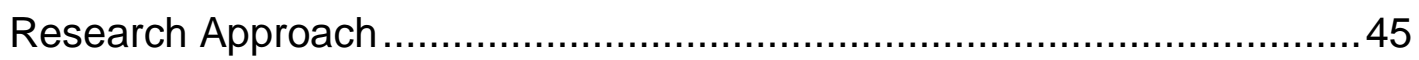

Heideggerian Phenomenology ........................................................ 45

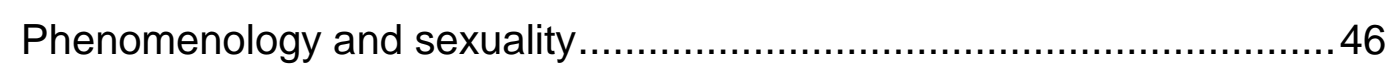

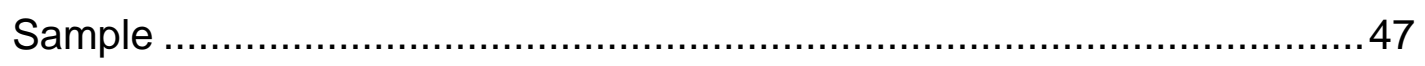

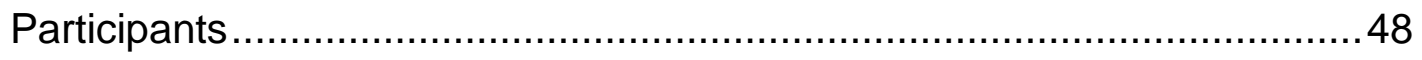

Table 1: Demographic Profile of Participants ............................................ 48

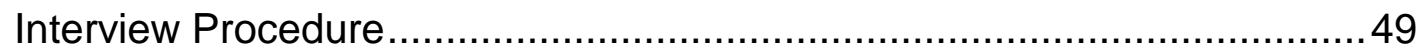

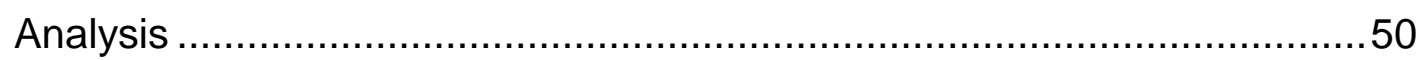

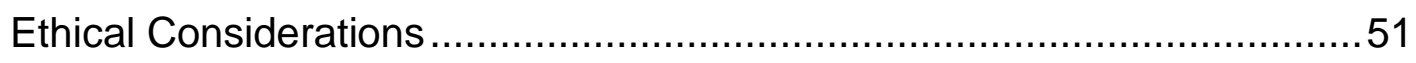

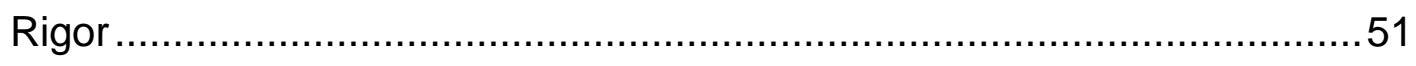

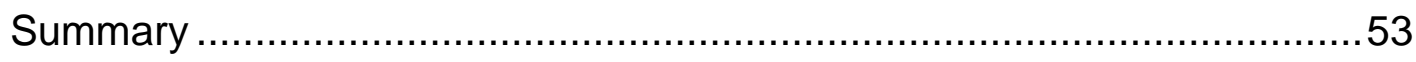

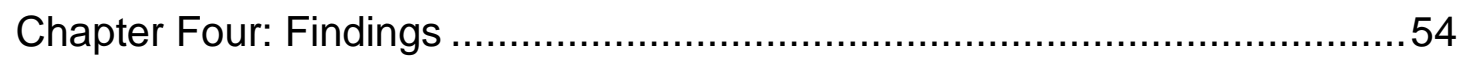

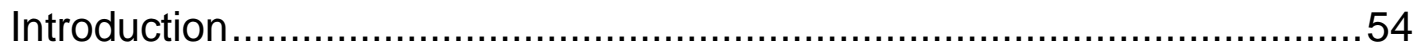

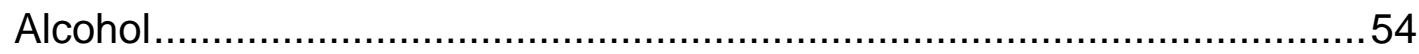

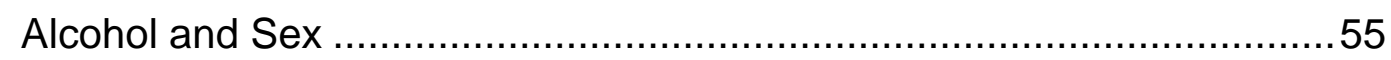

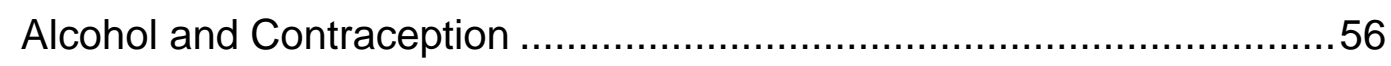

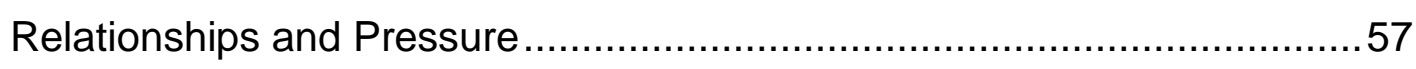

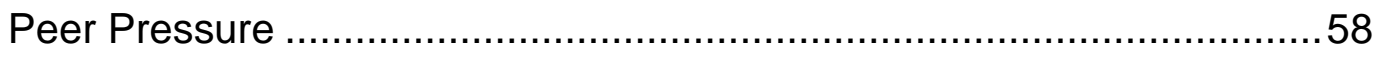

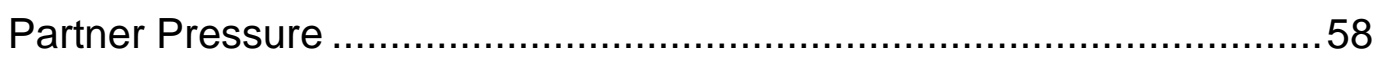

Internal Pressure and the Emotional Ramifications of Sex.....................59

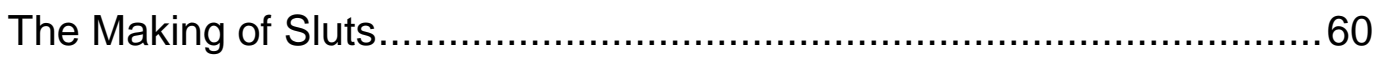

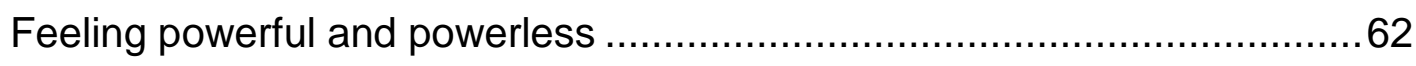

Getting information about sex outside of school ......................................63

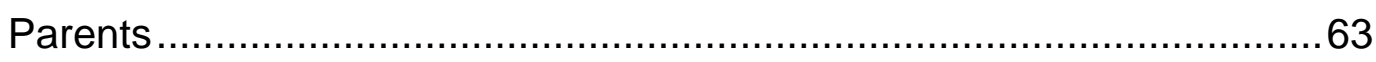

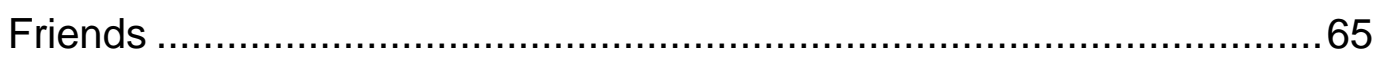

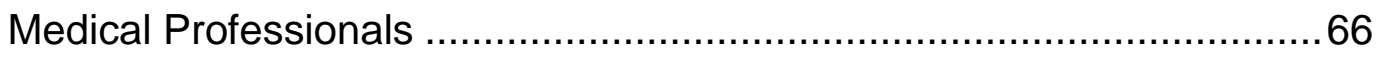

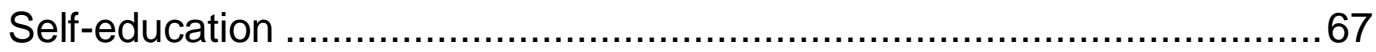

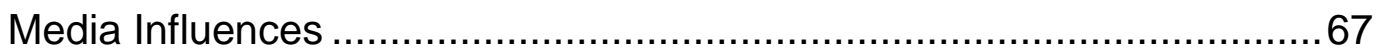

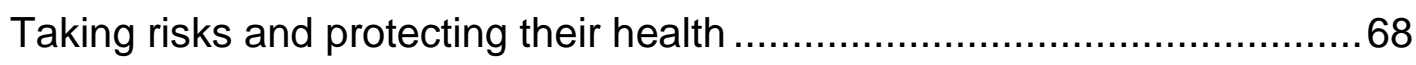

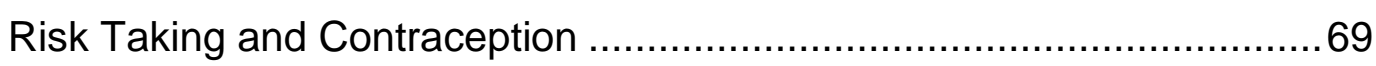

Taking responsibility for condoms ...................................................

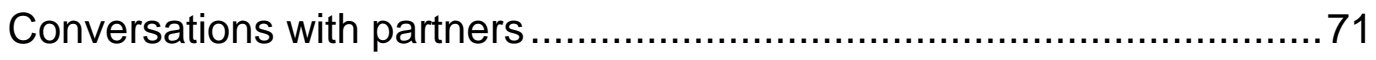

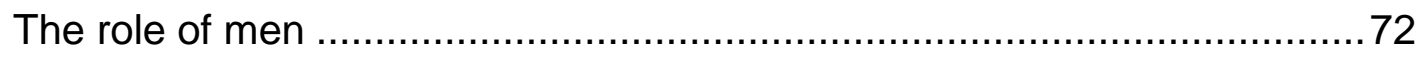


Education. .73

Recalling their own sexuality education..............................................

Ideas for improving sex education.................................................... 74

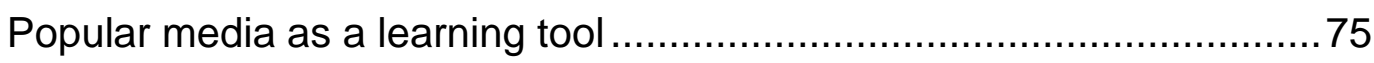

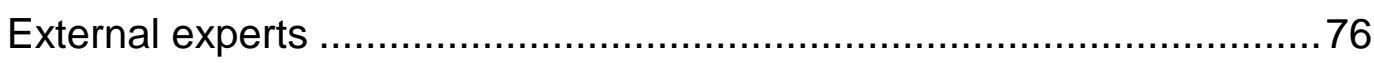

Grow the messages with the audience ............................................ 77

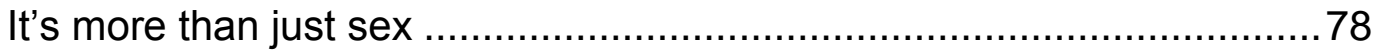

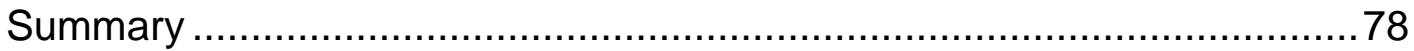

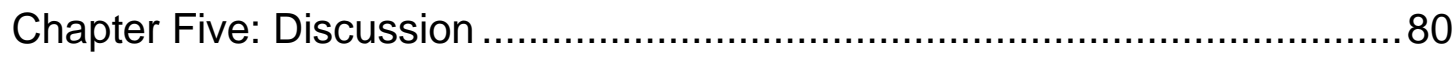

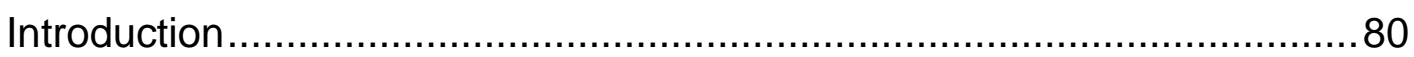

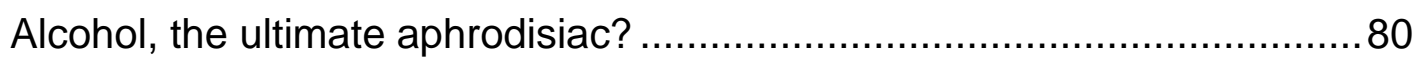

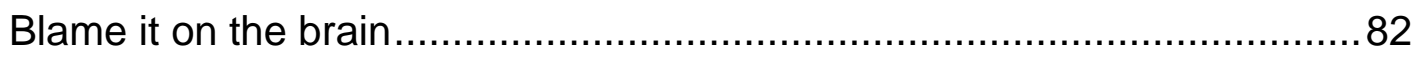

Making girls into ladies - socio-cultural influences ................................. 84

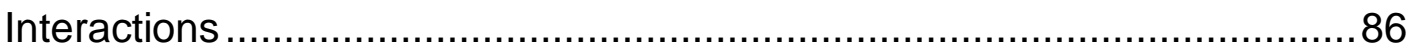

Figure 1: The interactions between the three key factors ...........................86

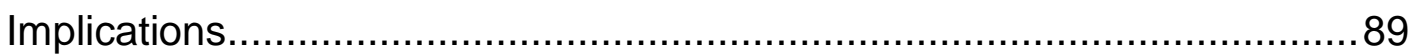

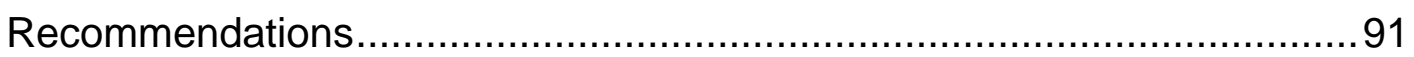

1. Desire and Pleasure - sex isn't all bad ............................................ 91

2. It will happen to you - the real risks .............................................92

3. Girls just wanna have fun - empowering women to take control of

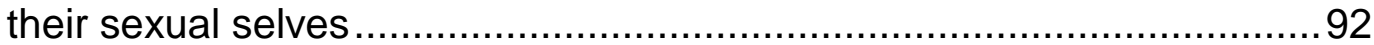

4. The New Zealand drinking culture .............................................93

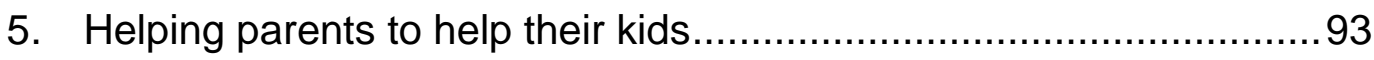

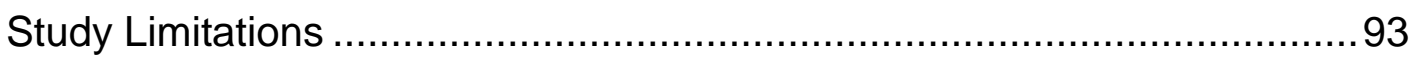

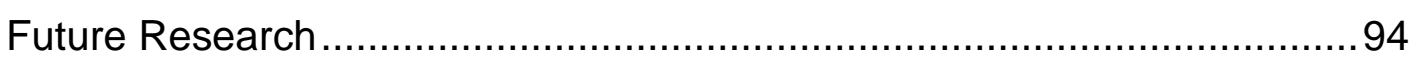

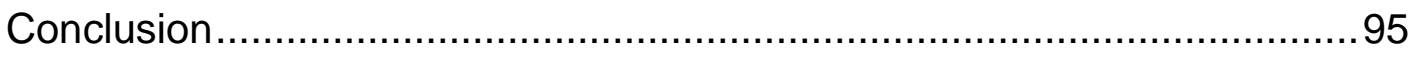

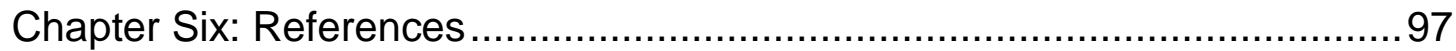

Appendix A: Recruitment Poster .......................................................113

Appendix B: Interview Guide ..........................................................114

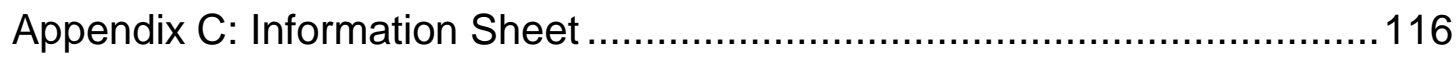

Appendix D: Consent Form..............................................................118 


\section{List of Tables and Figures}

Table 1: Demographic Profile of Participants .............................................. 48

Figure 1: The interactions between the three key factors .............................. 86 


\section{Acknowledgments}

Most importantly I would like to thank the women who participated in this research for generously sharing their experiences with me. With such an intimate and personal topic I was blown away by the open, frank and often detailed way they talked about their lives. To do that with a virtual stranger is no small feat and without that, this research would never have happened.

I would like to thank my supervisor Dr Barrie Gordon for being such a chilled out, Hawkes Bay, kind of guy. He has steered me through this whole process with gentle pressure and it has been a real pleasure to work with such an experienced researcher and teacher.

I would also like to thank my friends for listening to endless whinging about the process of doing a thesis and for the kind pats of the back pushing me forward. In particular, I would like to thank Dr Sally Rose and Anne Duncan, without whom this thesis would never have started or finished.

I would like to extend a huge thanks to my family, both in New Zealand and Canada, for putting up with me over the two years this has taken to complete. My mum for being utterly unsurprised in my ability to achieve my goals, please enjoy the reflected glory and my wife Melanie, for living the dream right along with me - it is definitely my turn to clean the bathroom. 


\section{Abstract}

New Zealand has high rates of sexually transmitted infections (STIs) and unwanted pregnancy when compared to other comparable countries. The purpose of this research was to gain a better understanding of how sexuality education in schools impacts young people's behaviour and to elicit their ideas for improving the curriculum. Data was collected using semi-structured interviews with eleven women aged 18-25. The research utilised Heideggerian phenomenology as a framework as this approach allows the researcher and participants to co-construct a shared understanding of the event/s.

The results outline a complex picture of young people's lives and their reasons for having both protected and unprotected casual sex. Three major themes were identified as increasing the likelihood of having casual sex: alcohol, biological factors and socio-cultural factors. However, none of these factors alone explain risky sexual behaviour. Rather, the factors interact within and between each other to increase or decrease the likelihood of someone having casual sex. This added complexity should be taken into account when consideration is being given to the way sexuality education in schools is taught. The results from this study add to the growing body of evidence that sexuality education in high schools need to change if it hopes to reduce the rates of teenage pregnancy and sexually transmitted infections.

Key words: Sexuality education, Heideggerian phenomenology, STIs, teenage pregnancy, casual sex, qualitative research 


\section{Chapter One: Introduction}

Sexuality education has been a compulsory part of the state school curriculum in New Zealand since 2001 following the introduction of the Education Standards Act. Despite this, teenage pregnancy rates have remained high, young people under 25 have the highest rates of sexually transmitted infections (STIs) of any age group in New Zealand, and are more likely to have concurrent infections (Statistics New Zealand, 2012; STI Surveillance Team, 2011). Unprotected casual sex is an important contributor to these statistics. Casual sex is predominately considered opportunistic rather than planned and is more likely to occur when alcohol or drugs are involved. The Youth 2007 survey found that $15 \%$ of sexually active New Zealand secondary school students used contraception only sometimes (Adolescent Health Research Group, 2008). The potential consequences of having unprotected sex can radically alter the course of a young person's life and may affect their physical and mental health or their long term life and career goals.

If school based sexuality education is to be effective in equipping young people with the skills to safely negotiate adult sexual activity, it needs to be aligned with the realities and challenges associated with adult romantic relationships. Sexual health is taught within the wider sexuality education component of the health and physical education curriculum (Ministry of Education, 1999). A 2007, Education Review Office (ERO) evaluation found "that the majority of sexuality education programmes were not meeting students' learning needs effectively" (Education Review Office, 2007a, p. 34).

\section{Casual sex}

Casual sex can be defined a number of ways (Weaver, 2008). In this research, the researcher has chosen to define it as 'having sexual intercourse with someone without the attachment of a romantic relationship, this is most often a one night stand with a stranger'

Casual sex is generally considered to be risky to a persons physical health as there may not be any knowledge of their partners sexual health status 
(Manning, Longmore, \& Giodano, 2006). Having casual sex is also linked closely with other risk taking behaviours such as alcohol consumption and drug taking (Grello, Welsh, \& Harper, 2006). Alcohol and drug taking have also been shown to reduce the likelihood of a person using condoms when they have sex (Coleman \& Cater, 2005; Kiene, Barta, Tennen, \& Armeli, 2009).

From a social perspective, casual sex seems to be becoming more and more acceptable behaviour for young people with research showing that "the majority of sexually active teens have had some sexual experience outside of a romantic relationship" (Manning, Longmore, \& Giodano, 2005, p. 384).

\section{Physical health}

A common consequence of engaging in sex without a condom is contraction of a STI. STIs can have both immediate and long term impacts on a person's health. In New Zealand, those aged 25 years or less have the highest rate of infection across all types of STIs, with the exception of syphilis, and are more likely to have multiple infections (STI Surveillance Team, 2010). Many STIs, especially bacterial infections such as Chlamydia and Gonorrhoea, are easily treated if detected early (Family Planning Association, 2011b). However, when left untreated some STIs can lead to infertility (Brady, 2003) and negative pregnancy outcomes such as preterm delivery and ectopic pregnancy (Blas, Canchihuaman, Alva, \& Hawes, 2007; Ministry of Health, 2008; STI Surveillance Team, 2010).

The most prevalent STI in New Zealand for 18-25 year olds is Chlamydia (STI Surveillance Team, 2011). Chlamydia can be asymptomatic in up to $70 \%$ of women and $25 \%$ of men meaning that unless young people are regularly engaged in screening tests they may not know they have it (STI Surveillance Team, 2011). In a 2008 qualitative study that asked young people about Chlamydia testing the authors found that young people were misinformed about Chlamydia and the way it is diagnosed (Rose, Smith, \& Lawton, 2008). The participants highlighted they didn't get tested due to the stigma and fear of having an STI. 
One STI that has been receiving a lot of medical and media attention in recent years (thanks to the development of a vaccine) is the human papillomaviruses (HPV). There are around 40 strains of HPV; some cause genital warts while others have been found to cause cervical, anal and oral cancers (Clifford, Smith, Aguado, \& Franceschi, 2003; Goldstone \& Moshier, 2010; Smith et al., 1998). The Centre for Disease Control and Prevention (CDC) in the United States estimates "almost all cervical cancers are caused by human papillomavirus (HPV)" (Centre for Disease Control and Prevention, 2012). As with Chlamydia, HPV is often asymptomatic, meaning people do not know they have contracted it (Centre for Disease Control and Prevention, 2012). Like other STIs, HPV transmission is significantly decreased through the consistent use of condoms. In an American study, young women who used condoms every time they had sex, had significantly lower rates of HPV infection than those who used them infrequently (Winer et al., 2006).

\section{Mental Health}

As teenagers grow and experiment with sex and relationships they begin to see there can be complex emotions that can be associated with sex, emotions they may not be prepared for. Research has found that there are differences in the way men and women react to having casual sex. An American study with college age students found males were more likely to engage in casual sex than females, but women were more likely to exhibit depressive symptoms afterward than men (Grello, et al., 2006). Interestingly though, the authors also found that the more depressive symptoms a woman had, the more likely she was to have casual sex (Grello, et al., 2006). This cyclical pattern of depressive symptoms/casual sex/depressive symptoms has also been linked to increases in the number of sexual partners a woman has (Fielder \& Carey, 2010). Feelings of regret are a major theme arising in the literature on casual sex. Young people are more likely to express regret if they did not use condoms and they were drinking alcohol (Coleman \& Cater, 2005). 


\section{Unplanned pregnancy}

Another potential consequence of engaging in unprotected sex is pregnancy. The teenage birth rate in New Zealand (defined by Statistics New Zealand as 15-19 years) has remained constant at around 31 per 1000 births since the mid 1980s and is higher that socially comparable countries such as the Norway, Australia, and Germany (Abortion Supervisory Committee, 2011; Statistics New Zealand, 2012; UNICEF, 2001). Maori women aged 20-25 have the highest overall birth rate in New Zealand, almost double that of the other ethnic groups in the same age category (Abortion Supervisory Committee, 2011; Statistics New Zealand, 2012). While some of these pregnancies will be intended, many are unplanned and result in termination. Results from the Dunedin Multidisciplinary Health and Development Study reported in 2002 that $60 \%$ of women in their cohort who fell pregnant before the age of 25 categorised the pregnancy as unwanted (Dickenson, Wilson, Herbison, \& Paul, 2002).

Currently, women aged 20-24 have the highest overall rates of pregnancy termination of any age group (Abortion Services in New Zealand, 2006; Statistics New Zealand, 2011a). Termination of pregnancy is a relatively minor and safe procedure physically, but there is debate about the long term psychological effects it may have on women. Research has shown some women would benefit from ongoing support following a termination as they may be more at risk of depression or anxiety disorders (Lipp, 2009). Factors which may increase a woman's likelihood of depression post abortion is pressure from their partner to have the termination, prior mental health issues and low self esteem (Lipp, 2009).

De Genna, Larkby \& Cornelius (2007) found "early use of alcohol and use of alcohol during first coitus may be risk factors for problematic alcohol use before pregnancy and during pregnancy among childbearing teenagers" ( $p$. 2799). Given the already established link between alcohol and casual sex, this could be a major health concern for pregnant teenagers. 


\section{Social impacts}

If a young woman gets pregnant during her teenage years she is less likely to continue her education which can have negative flow on effects into adult life for herself and her family (Skinner et al., 2009). It may mean she does not finish school which can result in reduced earning potential and career prospects (Skinner et al., 2009). The educational qualifications of a mother have also been shown to be the strongest positive predictor of a child's academic and social outcomes as they grow up (Sylva et al., 2008).

In New Zealand there are specialised teenage parent education units (TPUs) which are 'hosted' by a state run school. TPUs have onsite day-care for children while their parents are in classes. There are 19 TPUs located around New Zealand and places are limited. In 2011, ERO completed an evaluation of 18 of New Zealand's TPUs and found that there was wide variation in achievement by the students at each school (Education Review Office, 2011). It is estimated that, "the number of students enrolled at the 18 TPUs in this evaluation represents approximately 12 percent of teenagers who had babies in 2009" (Education Review Office, 2011, p. 3). The geographical location of TPUs and a limited roll means not all teenage parents will be able to utilise these services. This highlights some of the difficulty faced by young people juggling full time schooling and full time parenting.

\section{Research question}

The impact of the current sexuality education programme on the behaviour of sexually active young people is not well understood. One could argue that if sexuality education was effective, then rates of abortions, STIs and live births to teenage mothers should be considerably lower than they are. This research will attempt to address this gap in our knowledge about the impact of sexuality education on behaviour by interviewing young people about their experiences of casual sex. Participants will include young people who are sexually active and can therefore give context and examples of real life experience rather than answering how they think they might act, or would like to act should a specific situation arise. Participants will be asked to reflect on their own 
sexuality education and make suggestions for improvement given their experiences as sexually active young adults.

The objectives of this research are to:

- Understand the lived experiences of young women who are having casual sex without condoms. By drawing on real life examples of when they have casual sex without a condom the participants are able to reflect on factors that contribute to their decision making process.

- Understand participants experiences of their own sexuality education, both formal and informal.

- Draw on participant's ideas for improvements in the school based sexuality curriculum based on their experiences.

- Elicit information to drive the creation of new ideas for more effective sexuality education in schools.

\section{Thesis outline}

Chapter One of this report has grounded the research in context and considered why the work is important. This includes discussion of the health and social impact for young people of having casual sex without condoms. The chapter also discusses the central research objectives.

Chapter Two outlines the relevant research and literature available and is split into two sections. Firstly it covers the relevant literature affecting young people's use of condoms during casual sex and secondly considers the research on sexuality education from New Zealand and internationally. The chapter concludes by considering examples of successful sexual health education programmes and what parts of those programmes might be relevant for the New Zealand context.

Chapter Three provides a description of the research approach and methods. It begins by discussing the relevance of using Heideggerian phenomenology and how the underlying theory fitted into the research practices. This chapter also describes the participants, research procedure and the project tools. 
Chapter Four presents the findings of the interviews. It is structured around the broad themes which emerged from the analysis about why people have casual sex without condoms and what promotes or protects a person from that behaviour. The broad themes are alcohol, relationships and pressure, feeling powerful and powerless, getting information about sex outside of school, taking risks with their health, the role of men and experiences of sexuality education.

Chapter Five concludes this research with a discussion of the major findings of the work and how they are situated within the relevant literature. It also discusses the limitations of the study and offers suggestions for future research. Finally, the chapter presents a series of recommendations for school based sexuality education programmes. 


\section{Chapter Two: Adolescence and sex}

\section{Introduction}

Adolescence is more than a developmental phase. For young people, the onset of puberty marks the beginning not only of a number of biological changes but also a change in their place in society as they become adults. Adolescence is also a time of testing boundaries and trying new experiences that may include experimenting with sex, alcohol and relationships. These forces combine to heavily impact on aspects of a young woman's sexual identity, her sense of self and behaviour in certain situations. In order to navigate these changes safely, young women need access to good quality information and education about sex and sexual health.

The first half of this chapter focuses on the various social factors which influence the development of a young woman's sexual identity and the impacts of the biological changes that are co-occurring. It also explores the role of substance use and relationship status in young women having unprotected casual sex and which factors might protect against risky behaviour. The second half of the chapter explores the current status of sexuality education worldwide and then focuses on school based education in New Zealand. Finally, the chapter considers what kinds of sexuality education programmes have worked, in what contexts and what New Zealand might be able to learn from those examples.

\section{The development of a sexual identity for young women}

Modern society has different expectations of men and women; how they dress, how they act, what sports they play and what careers they might take up. Young people receive messages, some overt and some hidden, about these expectations through a variety of channels such as the media and their peers. In schools, this is known as the 'hidden curriculum', and is described as, "those unstated values, attitudes, and norms which stem tacitly from the social relations of the school and classroom as well as the content of the course" (Pitts, 2003, p. 282). The hidden curriculum plays a part in reinforcing 
stereotypes of behaviour and in influencing student's subject choices (Marshall \& Reinhartz, 1997). Research has also shown that teachers treat students differently based on their gender and reinforce socio-cultural norms through their own modelling behaviour (Marshall \& Reinhartz, 1997).

There has always been concern for young women who step outside of society's norms. In 1954 the New Zealand government commissioned an inquiry into the youth culture of the time looking into sexual immorality, sexual delinquency and the 'destabilising effect' of contraceptives (Mazengarb, 1954). The report produced by the committee was titled, "Report of the Special Committee on Moral Delinquency in Children and Adolescents" and held special concern for young women stating

"In former times it was the custom for boys to take the initiative in seeking the company of girls; it was conventional for the girls to await any advances. Nowadays, girls do not always wait for an advance to be made to them, nor are they as reticent as they used to be in discussing intimate matters with the opposite sex. It is unfortunate that in many cases girls, by immodest conduct, have become the leaders in sexual misbehaviour and have in many cases corrupted the boys". (Mazengarb, 1954, p. 18)

While we may think the Mazengarb report is no longer socially relevant, in April 2011, Canadian Police Constable Michael Sanguinetti sparked a number of protests when he told students at a Toronto school, "I've been told I'm not supposed to say this - however, women should avoid dressing like sluts in order not to be victimised" (Associated Press, 2011, para. 8). In protest at this comment a series of protests known as 'slut walks' were held in cities around the globe. One participant was quoted as saying, "Being in charge of our sexual lives should not mean that we are opening ourselves to an expectation of violence, regardless if we participate in sex for pleasure or work" (Associated Press, 2011, para. 11). The comment made by the police officer shows there is still a belief in society that if women dress in a certain way, they must take responsibility for being sexually assaulted. There is also the 
implication that women are sexual objects and must take responsibility for giving the wrong idea to men based simply on the clothes they wear. For young women, this kind of comment reinforces the traditional gender stereotyping that a man's sexual desire is outside of his control so women should remember the onus is on them to appear non-provocative so men won't be tempted. However, there is no hard definition on what constitutes as non-provocative dress, and many cultures have differing opinions.

For society there remains an on-going discomfort with women, and particularly young women, expressing their sexuality through the way they dress or act. Most often, people consider this to be an issue of their morality. In sexuality literature young women are described as being subjected to "conflicting standards of femininity that demand they be sexually desirable and chaste at the same time, which often leads to confusion surrounding sex, dissociation from sexual feelings, and uninformed decisions about sex" (Tolman, as cited in Gilmartin, 2006, p. 429). It is also important to note that while men are often cast into the role of always wanting sex, research has found men struggle with the complexity of their gender role. They also found some young men lack the ability to cope with their feelings (Paul \& Hayes, 2002).

The advent of modern contraceptive technology sparked a new era for women. The intended consequence of the invention of the female contraceptive pill was to prevent unwanted pregnancy. However, it also had the additional impact of placing women in complete control of their fertility for the first time. They could now choose when and how many children they could have over their reproductive life time. While this may seem in some ways innocuous, it also meant women could choose to have sex for pleasure. The median age of mothers in New Zealand in the late 1960s was 26, whereas in 2011 it was 30 (Statistics New Zealand, 2011b). This suggests that women are choosing to do other things with their lives before having children. Today's young women have grown up in a world where the contraceptive pill is not only widely available, but its use encouraged. 
Young women are also experiencing physical changes as they mature, which can be conflicting and contradictory to the messages they are receiving from society. Their bodies are going through the process of puberty which biologically results in changes in hormones, leading to physical sexual desire (Stang \& Story, 2006). However society, and the social construction of gender norms, tells them they should not give into these urges and should remain wanted but not wanting, "we have effectively desexualised girls' sexuality, substituting the desire for relationships and emotional connection for sexual feelings for their body" (Tolman, 2003, p. 5). These kinds of conflicting pressures, which start at puberty, can create confusion for young women. They can end up unsure of where their physical desires sit in relation to the social expectations for wanting relationships "don't be a prude but don't be a slut" (Tolman, 2003, p. 7).

When it comes to casual sex and contraception, these conflicts can have negative outcomes. In one New Zealand study, teenage girls reported not wanting to carry condoms as doing so may make them seem like they were promiscuous and planning to have sex (Abel \& Brunton, 2006). In general, girls did not want to be perceived as having a negative reputation and so would rather have "unexpected" sex than risk being seen in a negative light (Kirby, 2007; Lesta, Lazarus, \& Essen, 2008; Makenzius, Gadin, Tyden, Romild, \& Larsson, 2009). Girls could be putting their own sexual health second to their fear of being perceived negatively by society.

Positive self esteem and self efficacy (belief in themselves) has been found to encourage safe sexual practice. Studies show females with higher selfefficacy are more likely to have protected sex, even in casual situations (Byno, Mullis, \& Mullis, 2009; Manning, et al., 2005; Suvivuo, Tossavainen, \& Kontula, 2009). Having low self-esteem means women are more likely to make unhealthy decisions regarding their sexual health such as having unprotected sex. They also report having feelings of guilt and feeling lower self-esteem after having casual sex (Herold \& Mewhinney, 1993; Tolman, 2003). 


\section{The influence of Religion}

For many women in New Zealand, religion has a major influence in their lives. The 2006 New Zealand census reported $55.6 \%$ of the population had a religious affiliation (Statistics New Zealand, 2006). Religion and religious teachings have an influence over society, especially in defining 'morals' or 'values'. A person not being religious themselves does not mean that the society they live in has not been shaped by its teachings.

The Catholic Church in particular has very strong views on contraception, especially condoms. While there is no real way to count, estimates show there are over 1 billion people who consider themselves Roman Catholic (BBC News, 2005). The churches doctrine bans the use of contraception or birth control of any form as it is seen as preventing new life coming into the world (Brom, 2004). Again, these messages create a conflict for women who may want to have sex for pleasure, but feel it would be against their religious teachings to do so. Roman Catholic teachings centre on pregnancy and the blocking of new life. However, in 2010 Pope Benedict XVI stated in an interview that condoms may be useful in rare cases, such as for male prostitutes, to reduce the spread of HIV/AIDS (Donadio, 2010). While the church's official position is still that contraception or birth control is not to be used in any form, this shows that the church may consider there is more to sex than just reproduction. Other mainstream Christian based religions such as Anglican, Methodist and Presbyterians actively support the use of contraception for family planning (The Church of England, 2005; The General Board of Church and Society of the United Methodist Church, 2008; The Presbyterian Church of the USA, 2010).

\section{The developing brain and risk taking}

During adolescence there is a great deal of growth and development happening in the body and the brain. There is significant scientific evidence that human brains do not finish maturing until around the age of 25 , and that the last stage of brain maturation includes "areas involved in planning and decision-making, including the prefrontal cortex, the cognitive or reasoning 
area of the brain important for controlling impulses and emotions" (Society for Neuroscience, 2007, p. 2). During adolescence the "brain's reward centre, the ventral striatum, also is more active" (Society for Neuroscience, 2007, p. 2). This means for young people the areas of the brain they would used to consciously weigh up the risks and benefits are still developing. Without being able to fully process all their emotions and having a fully active 'reward centre', young people are biologically on the back foot when it comes to being able to act rationally in regards to sexual health. If they are seeking an experience that makes them feel good, then sex is an obvious choice. However, they are perhaps not able to completely consider all the implications of those actions, which could include the results of not using contraception.

How a person responds to a situation could be as simple as the wording used to describe the risk. Tversky and Kahneman (1986) coined the term 'framing' to describe how simple changes in the phrasing of a sentence (a 'gain' versus a 'loss') affect a person's preference for choosing an outcome, even if the outcome of each sentence is identical. The most well known example of framing as positive or negative outcome is known as the "Asian Disease Problem".

Imagine that the U.S. is preparing for the outbreak of an unusual Asian disease, which is expected to kill 600 people. Two alternative programs to combat the disease have been proposed. Assume that the exact scientific estimate of the consequences of the programs are as follows:

If Program A is adopted, 200 people will be saved. [72 percent] If Program B is adopted, there is $1 / 3$ probability that 600 people will be saved, and 2/3 probability that no people will be saved. [28 percent]

Which of the two programs would you favor?

Then using a second group of participants: 
Problem 2: If Program C is adopted 400 people will die. [22 percent]

If Program $D$ is adopted there is $1 / 3$ probability that nobody will die, and $2 / 3$ probability that 600 people will die. [78 percent] Which of the two programs would you favor? (p. 453)

The purpose of the task is to use essentially the same outcomes with one framed as a gain scenario (more people saved) and the other as a loss scenario (more people die). This study has been replicated many times with Kuhbeger Schulte-Mecklenbeck, \& Perner (1999) stating that, "presenting outcomes as gains tends to induce risk-adverse choices, and presenting outcomes as losses tends to induce risk-seeking choices" (p. 227). Young people may be hearing information about pregnancy risk and STIs in terms of losses rather than gains, creating a negative framing effect which influences their choice to take a gamble and engage in risky sex.

Research into how people make decisions that involve risk also demonstrates that adolescents are effectively caught between two developmental modes. The first, known as verbatim analysis is an empirical weighing up of the cost and benefit of a decision. Verbatim analysis employs the belief that the world is a rational place and computes the decision under that framework. The second decision making process is known as gist-based analysis and is influenced by the "meaning an individual extracts from the information, which reflects the individual's knowledge, understanding, culture and development" (Rivers, Reyna, \& Mills, 2008, p. 109) to form the basis of a decision. Gistbased decisions take into account more than the simple risk and reward of the action itself. It will consider longer term consequences and include them in the decision making process. An example used in the literature shows that; if a young woman is deciding whether to have unprotected casual sex using verbatim analysis she would weigh up the relative risk of getting pregnant (low) with the pleasure of the outcome (high) and go ahead. If she were using gist-based analysis she would likely admit that while the risk of getting pregnant is low, the long term effects should she get pregnant would change her desired life course (not finishing high school, going to university, travel 
etc.). This suggests she would calculate the longer term implications of getting pregnant to raise the risk to above acceptable for the immediate terms pleasure of having sex (Reyna et al., 2011).

Verbatim and gist-based risk analyses are developmental stages. Research clearly shows that as people move from childhood to adolescence and into adulthood they rely less and less on verbatim analysis and more on gistbased analysis (Grose-Fifer, Hoover, Zottoli, \& Rodrigues, 2011; Reyna, et al., 2011; Rivers, et al., 2008). Grose-Fifer et al, (2011) also found that "given the time and few cognitive or emotional demands, adolescents are likely to be successful in identifying what constitutes a risk. However, under stress, adolescents are at a disadvantage because they cannot benefit from the cognitive shortcuts that adults use to rapidly identify a risky situation" ( $p$. 1190). Rivers et al (2008) adds, the importance of emotions in the risk assessment process, "discrete emotional states influence whether processing is gist-based as opposed to verbatim-based, which, in turn, governs risky decision making" (p. 136). It is likely that when it comes to making decisions about casual sex, young people will be faced with other stimuli such as peer pressure or alcohol and drugs. This would not allow them the space they need to fully estimate the risk of the situation.

\section{The Developing Brain and Alcohol}

Alcohol affects a person's basic cognitive functioning. Studies have shown that ethanol, the psychoactive feature of alcohol, effects the functioning in a number of areas of the brain including the frontal lobe and limbic system (Oscar-Berman \& Marinković, 2007). The limbic system and the frontal lobes are also key pathways for dopamine, a chemical that creates feelings of pleasure or reward (Koob, 2003). As stated previously, the prefrontal cortex and the limbic system are the key areas young people use to make decisions (Casey, Jones, \& Hare, 2008). The effects of alcohol are even more pronounced when young people binge drink. Research on the brains of young adults has shown physical changes in the structure of the prefrontal cortex in those who binge drink (Crego et al., 2010). Some young people may damage 
their brains enough with binge drinking that their prefrontal cortex never fully develops.

\section{Young People, Relationships and Sex}

Relationships can be classified in many ways: long term, casual, one-night stand, romantic/non-romantic, "hooking up" etc. Each of these terms implies a varying level of commitment to the other person, from a confirmed public relationship to a single sexual encounter with a stranger. It is important to note that hooking up does not have to be or result in vaginal intercourse. Paul \& Hayes (2002), defined hooking up as "sexual encounters between two people who are brief acquaintances or strangers, usually lasting only one night without the expectation of developing a relationship" (p. 639). This broadening of the definition is important from a health perspective. For many women the primary concern when deciding on a birth control method is preventing pregnancy rather than protection against STIs. This means they are more likely to choose oral contraceptives or other non-barrier methods which offer no protection against STIs (Abel \& Brunton, 2005). While pregnancy is only a risk in unprotected vaginal intercourse, STIs can be transmitted through anal and oral intercourse (Goldstone \& Moshier, 2010; Smith, et al., 1998). In an American study of college students and casual sex, none of the participants reported ever having used condoms or dental dams as protection from STIs during oral sex (Downing-Matibag \& Geisinger, 2009).

Research shows that the definition or type of relationship itself can also have an impact on whether condoms are used. For instance, young people who define themselves as being in long-term or committed relationships will be more likely to use condoms than those in casual relationships (Coleman \& Cater, 2005; Raine et al., 2010). This higher rate of use can be attributed to more open communication about wanting to have sex and use contraception, which can lead to planning for and having protected sex (Ryan, Franzatta, Manlove, \& Holcombe, 2007). For that reason people engaging in casual sex are also less likely to use contraception (Ford, Sohn, \& Lepkowski, 2001). Research also shows that often casual or non-romantic sex is reported as 
being more spontaneous and contraception is therefore less accessible ( $\mathrm{S}$. Brown \& Guthrie, 2010; Van Empelen \& Kok, 2006).

Young people who discuss sex and sexuality with their parents are also more likely to be open to discussion with partners (Ogle, Glasier, \& Riley, 2008; Whitaker, Miller, May, \& Levin, 1999). However, young people frequently state their most trusted source of sexual information is their friends (Makenzius, et al., 2009). Young people also discuss sex and sexual encounters with friends if they viewed them as positive, and less likely if they viewed the experience as negative leaving them to stew internally on their regret for the encounter (Paul \& Hayes, 2002). This was especially likely if they considered their partner would be judged unattractive by their friends (Coleman \& Cater, 2005; Paul \& Hayes, 2002).

For men the issue of contraception use is also based on perceived relationship status. In a 2010 study young men age 19-26 in San Francisco who were predominantly in casual relationships talked about their use of condoms (Raine, et al., 2010). The men reported that while use of a condom to prevent STIs was important, their main concern was pregnancy. However, their behaviour was not always in line with their stated intentions. In some cases, the lack of contraception use was attributed to a low regard for the women they were involved with. The study concludes that higher levels of intimacy between partners can increase the use of contraception (Raine, et al., 2010).

\section{Alcohol/drugs and Unprotected Sex}

The negative effect of alcohol on safe sex practices is well documented internationally. A qualitative study of 64 English adolescents aged 14-17 years, found that young people had five general areas of explanation/excuse for why alcohol led to more risky-sex; "1) alcohol affecting young people's assessment of a person's sexual attractiveness, 2) alcohol used as an "excuse" for socially unacceptable behaviour, 3) increased confidence and lowering of inhibitions, 4) impaired judgement in accurately recognizing and controlling a potentially risky situation, and 5) complete loss of control, 
memory loss, and "black-out"' (Coleman \& Cater, 2005, p. 649), all of which effectively act as nullification of the actions. In a daily diary study of university students in the United States (Kiene, et al., 2009), drinking alcohol was associated with increased likelihood of sex with a causal partner. For women, the more alcohol consumed the more likely it was they would have sex without protection (Kiene, et al., 2009). The same correlation between causal, unprotected sex, and alcohol was also found for both genders in an Irish study (Cousins, Mc Gee, \& Layte, 2010). Interestingly, Paul \& Hayes, (2002) found that when college students were talking of their best and worst hook up experiences, alcohol was a prominent feature in both instances.

A study in the United States showed that for young people compulsive drinking is linked to increases in other risky behaviours such as illicit substance use and gambling as well as unprotected sex (Pedrelli et al., 2011). In a European study, researchers found that some people used alcohol to help them have sex and consequently were more likely to have sex without using a condom and to have regretted having sex after using alcohol or drugs (Bellis et al., 2008). The study also found that people who regularly use cocaine were also more likely to have unprotected sex while cannabis and ecstasy were correlated with having sex that they later regretted (Bellis, et al., 2008).

Young people who use alcohol and/or drugs are putting themselves at an increased risk of STIs and unintended pregnancy. In a report by the Ministry of Health published in 2009, people aged 18-25 had the highest rates of drinking to feel drunk and consuming large amounts of alcohol in single sessions. This finding was consistent for both males and females (Ministry of Health, 2009). New Zealand's binge drinking culture at late adolescence is also well studied (Kypri \& Langley, 2003; Kypri, Langley, McGee, Saunders, \& Williams, 2002; Kypri et al., 2009; McGee, Williams, \& Kypri, 2010) and reported on in the media, "Severely drunk women shock police" (Ash, 2010). A recent statistical analysis between binge drinking and STI prevalence in a New Zealand university student cohort found "that the links between alcohol and STI are due to the disinhibiting effects of alcohol, resulting in increasing 
levels of impulsive sexual behaviour and unsafe sexual practices, and increased risk of exposure to STI" (Boden, Fergusson, \& Horwood, 2011, p. 5)

The link between alcohol and sex also has a place in popular culture. A number of songs feature the use of alcohol and some actually popularise the idea of blaming alcohol for actions. Jamie Foxx's Blame It include the lyrics, "she said she usually don't, but I know that she front, 'cause shawty know what she want, she don't wanna seem like she's easy" (J. T. Brown et al., 2008, track 5), which is about a girl using alcohol as an excuse to have sex with someone when she doesn't want to seem 'slutty'. This kind of excusing behaviour for women is well documented in research as women don't want to appear as though they are 'easy' (Hillier, 1998; Lesta, et al., 2008; Makenzius, et al., 2009). The country song 'Need you now' by Lady Antebellum features "It's a quarter after one, I'm a little drunk, and I need you now, said I wouldn't call, but I've lost all control, and I need you now" (Haywood, Kear, Kelley, \& Scott, 2009, track 1), which is reference to a 'booty call', which is calling someone only when you are drunk for casual sex. While there is no causal effect established between pop music, sex and alcohol consumption, what it really reflects is the place of alcohol in our culture. Popular music appeals to people because they feel they can relate to the lyrics (Anuta, 2006). If the link between alcohol and sex is overtly portrayed in pop music, this could be considered a reflection of the reality of people's social experiences.

\section{Sexuality education internationally}

The 2009 report titled Internal Technical Guidelines on Sexuality Education produced by UNESCO, identified four 'minimum requirements' for a sexuality education programme;

- Information: sexuality education provides accurate information about human sexuality

- Values, attitudes and social norms in consideration of the principles of tolerance, respect, gender equality, human rights, and equality

- Interpersonal and relationship skills 
- Responsibility: sexuality education encourages students to assume responsibility for their own behaviour as well as their behaviour towards other people through respect (UNESCO, 2009, p. 5)

The report goes on to state that a programme should have clear goals for behaviour change, develop culturally relevant and sensitive tools and be piloted with feedback from the students (UNESCO, 2009).

The content, quality and quantity of sexuality education differs from country to country. In some countries, for example New Zealand and The Netherlands, it is explicitly mentioned in curriculum documents, while in others sexuality education is not included. Research on young peoples memories of sexual health education found they could remember very little of their sexuality education and would have liked more time spent on sexual health topics (Black, McGough, Bigrigg, \& Thow, 2005). A study of current students in Cyprus (where there is no formal sexual health curriculum) reported the students found what they were being taught repetitive and outdated (Lesta, et al., 2008) while a group of Canadian students found their lessons overgeneralized (Begoray, Wharf-Higgins, \& MacDonald, 2009). In relation to teachers, several studies reported that students felt their teachers were either unqualified or seemed embarrassed to discuss sexuality matters (Begoray, et al., 2009; Matziou et al., 2009). International literature shows that while a student's knowledge base on sexuality will increase naturally with age, (Westwood \& Mullan, 2006) school sexual health curriculums have a "narrow definition of adolescent sexuality" (Bay-Cheng, 2003, p.71) and need to expand into providing students with real life skills for dealing with sexual relationships, including aspects of sexual desire (Collins \& Champion, 2009; Wallace et al., 2007; Westwood \& Mullan, 2006). Students themselves report they would like teachers to view them as "sexual subjects, whose sexuality is not automatically constituted 'as a problem"' (Allen, 2005, p. 390) and would like sexual pleasure to be included in the discussion (Ingham, 2005). 


\section{Abstinence only programmes}

In 1996, the United States federal government announced \$50 million per year would be allocated to fund abstinence only education programmes. These programmes "require that abstinence be taught as the only option outside of marriage; discussion of contraception is either prohibited or its ineffectiveness in preventing pregnancy and STIs or HIV is highlighted" (Landry, 1999, p. 283). Research has shown that abstinence only education "prevents the development of a safe sex culture" (Weaver, Smith, \& Kippax, 2005 , p. 184) and that students who take chastity vows or virginity pledges are actually less likely to use contraception at first intercourse resulting in the possibility of an increased number of unwanted pregnancies (Bearman \& Brackner, 2001; DiCenso, Guyatt, Willan, \& Griffith, 2002). In a study of the Illinois public school district the author found that the increased pressure from government had led to a decline in teaching about contraception, abortion and sexual orientation (Lindau, 2008).

Countries such as The Netherlands and France are regularly lauded for having a high level of contraceptive use and low abortion rates for young people (Advocates for Youth, 2011; Ferguson, Vanwesenbeeck, \& Knijn, 2008; UNICEF, 2001; Weaver, et al., 2005). Along with discussion on reproduction and contraception, the Dutch sexual health curriculum also discusses communication and decision making as key elements in safe sex. The programme also stresses the best way to prevent pregnancy and STIs is the 'Double Dutch', using both condoms and hormonal birth control (Ferguson, et al., 2008). An important and unique aspect of these more open curriculums is that they do not discourage sexual intercourse, as is the case in abstinence education, but instead promote safety and responsibility which leads to better health outcomes for young people (Ferguson, et al., 2008). The curriculum also promotes understanding sexual desire and consideration of whether to become sexually active or not and how to communicate personal sexual boundaries and desires to a partner (Ferguson, et al., 2008). 
In France, like The Netherlands, the low youth STI and abortion statistics are attributed in large part to social acceptance of teenagers having sex. A 2001 Guttmacher Institute report which compared the high rates of unplanned pregnancy and STls in the United States to other countries (including Sweden) with lower incidence rates concluded:

societal acceptance of sexual activity among young people, combined with comprehensive and balanced information about sexuality and clear expectations about commitment and prevention of childbearing and STDs within teenage relationships, are hallmarks of countries with low levels of adolescent pregnancy, childbearing and STDs. (Darroch, Frost, \& Singh, 2001, p. 5)

\section{Sexuality Education in New Zealand}

Sexuality education became compulsory up to Year 10 within New Zealand state and state-integrated schools following the introduction of the Education Standards Act in 2001. The initial curriculum document was released in 1999 with the view that schools would have a two year transition period to implement the required changes (Dewar, 2001). Prior to this, health education was focused more on "personal development and self enhancement" (Sinkinson \& Burrows, 2011, p. 56) and sexual health was not mandated as a specific topic area in schools. The majority of sexual health education was led by Public Health Nurses (funded by the Ministry of Health), who had always maintained a presence in New Zealand secondary schools. In the mid 1980s, Public Health Nurses working in schools were directed for the first time to cover STIs and human sexuality with students in Forms 6 and 7 (Year 12 and 13) (Weir, 2000). In 1993, the role of Public Health Nurses was again changed, with some nurses focusing specifically on adolescent health (Weir, 2000). This new focus led to Public Health Nurses becoming involved in the professional development of teachers to increase "teacher competence and confidence in teaching the more clinical aspects of sexuality education" (Weir, 2000, p. 13). 
Despite the implementation of compulsory sexuality education in 2001, and interventions from the Ministry of Health, teenage pregnancy and STI transmission rates in New Zealand have remained stagnant at best (Statistics New Zealand, 2011b; STI Surveillance Team, 2011). However, the inclusion of sexuality education in the health and physical education curriculum has remained a controversial topic. Kane (2008) describes the controversy as "complex issues regarding the respective rights of parents, children and the state, between central and local government and between health campaigners and moral traditionalists" ( $p$. 5). It is possible that the controversial and often polarising nature of sexuality education is hindering its ability to have any real effect on the health outcomes of young people in New Zealand.

Sinkinson (2011), describes sexuality education as "controversial and sensitive" (p. 59) and this forms the basis for heated discussion between polarised groups.

What is demonstrated here is the strength - and the division - of opinion about what is and is not appropriate health education. The subject is exposed to greater scrutiny and criticism that any other school subject, and there is no shortage of community, parental and public opinion about what should happen (or not happen) in health education, and how it should happen (Sinkinson \& Burrows, 2011, p. 58)

Sexuality education in New Zealand is taught as part of the wider Health and Physical Education curriculum which consists of four strands: Personal Health and Physical Development, Movement Concepts and Motor Skills, Relationships with Other People and Healthy Communities and Environments (Ministry of Education, 2007). Underlying each strand is a series of aims and objectives setting the learning goals for students. The learning goals for sexuality education are, 
- Knowledge, understandings, and skills relating to sexual development - physical, emotional and social.

- Knowledge, understandings, and skills to enhance their sexual and reproductive health

- Personal and interpersonal skills and related attitudes, including

- The skills needed to examine people's attitudes, values, and beliefs and their rights and responsibilities

- Attitudes of respect for themselves and other people

- Attitudes of care and concern for themselves and other people

- Effective communication skills

- Problem-solving and decision-making skills

- Understanding and skills to enhance relationships. (Ministry of Education, 1999, p. 38)

The design of units and individual lesson plans to teach these strands are done by individual schools and teachers. This means that the provision of sexuality education in schools has the potential to vary widely in both topics covered (STIs, pregnancy, contraception, negotiation etc) and the number of lessons utilised (New Zealand Parliamentarians' Group on Population Development, 2006). The Education Standards Act also requires school boards of trustees to consult with the wider school community about how the health curriculum is taught and report on the way they will address the sexuality component (Ministry of Education, 1999). This is the only area of the curriculum that required consultation with parents.

In New Zealand, the Ministry of Health also plays a role in sexual and reproductive health education. The Ministry of Health has a number of resources available to aide teachers in their curriculum planning for sexuality education including booklets, videos and suggested lesson topics (Ministry of Health, 2003). Suggested lessons include contraception, STIs and 
relationships spread over six classroom based lessons (Ministry of Health, 2003). The Ministry of Health also has a range of factsheets on sexual health related topics available freely on their website which teachers can access (Ministry of Health, 2011).

Some schools will elect to bring outside providers, such as Family Planning Association (FPA) educators, public health nurses or other external agencies, to teach this component of the curriculum. The FPA also offers training courses for teachers and freely available sexual health information on their website (Family Planning Association, 2011a). One of the criticisms of having outsiders come to teach sexuality education is that "these agencies may provide their own viewpoints on sexuality and sexual health" (New Zealand Parliamentarians' Group on Population Development, 2006, p. 11).

In 2001, the Government released phase one of its Sexual and Reproductive Health Strategy recognising that while some interventions had been successful in addressing high STI and high unintended pregnancy rates, more targeted programmes were needed (Ministry of Health, 2001). The Ministry of Health recognised that meaningful change would require a cross-government initiative and input from private sector providers focusing beyond simply increasing personal knowledge, to changes in social values related to sexual and reproductive health. It was acknowledged that special emphasis needed to be placed on the needs of Maori, Pacific and young people (Ministry of Health, 2001).

Following the release of the sexual and reproductive health strategy, the Ministry of Health launched a health promotion style campaign to increase safe sexual health practices in 2004. The intended outcome was to decrease the rate of STIs for those in the 15-19 year old target audience (TNS, 2005). An evaluation of the campaign found that the messages were well accepted by the audience and many reported that they intended to change their behaviours (TNS, 2005). The scope of the evaluation meant it was unable to assess the long term effects of any behaviour change leading to a reduction in the rates of STIs. However, surveillance data since 2004 suggests the rates of 
infection for cases of Chlamydia and gonorrhoea have increased not decreased (STI Surveillance Team, 2010). This may be in part though due to an increase in screening, which would result in more cases being diagnosed. A 2008 study using 8 years of laboratory data from Waikato, found that increases in screening numbers correlated with some national advertising campaigns (Morgan, 2008). The study concluded "increased awareness leading to more testing and, in turn, greater detection of an asymptomatic infection such as Chlamydia trachomatis" (p. 47).

In 2006, the sexual and reproductive health of teenagers was the focus of a report by the New Zealand Parliamentarians' Group on Population and Development (NZPPD). Following a series of public submissions the report made 20 recommendations it considered key in reducing unintended pregnancy and STI rates for teenagers (New Zealand Parliamentarians' Group on Population Development, 2006). The recommendations covered a wide range of activities for improving sexual health in young people that would require resources from multiple government agencies to be successful. It was also acknowledged that "the provision of sexuality education varies greatly from school to school, and is a neglected area for some schools" (New Zealand Parliamentarians' Group on Population Development, 2006, p. 11). The report made the following recommendations specifically for school based programmes.

Recommendation 6: Evaluate all current youth sexual and reproductive health and education initiatives to develop a consistent nationwide programme.

Recommendation 7: Young people need consistent and comprehensive sexuality and relationship education in both schools and non-educational settings, delivered by trained specialist teachers or facilitators. Government must prioritise sexuality and relationships education, and ensure that all schools deliver comprehensive programmes. 
Recommendation 10: Develop and fund an integrated Youth Health Service Model to include school based services and mobile services. Every school should have a paid nurse able to offer sexual and reproductive health services. (New Zealand Parliamentarians' Group on Population Development, 2006, pp.

Following on from the release of the 2006 NZPPD report, the Education Review Office (ERO) was asked by a cross-sector reference group to address recommendation 6 and evaluate sexuality education in New Zealand secondary schools. The evaluation focused on:

- the quality and content of teaching and learning programmes in sexuality education provided by teachers in schools;

- the quality and content of teaching and learning programmes in sexuality education provided by outside providers to students in schools; and

- the extent to which teaching in sexuality education supports high quality learning outcomes for all students including Maori, Pacific, international, those of diverse sexual orientations and gender identities, those with special education needs, and those with strong religious or cultural beliefs. (Education Review Office, 2007a, p. 4)

ERO evaluated sexuality education programmes in $100 \mathrm{New}$ Zealand secondary and intermediate schools including state and state-integrated schools in 2007. The sample was chosen to be "representative of the school education sector in terms of the decile range and status (state or integrated)" (Education Review Office, 2007a, p. 6) Schools were asked to self-evaluate their sexuality education programmes and include documentation and evidence to support those self ratings. The evaluation found, "the majority of sexuality education programmes were not meeting students' learning needs effectively" (Education Review Office, 2007a, p. 2). Specifically the review 
noted that on average schools only dedicated 10 hours per year to teaching sexuality education and that under a third of teachers were specifically trained in sexual health (Education Review Office, 2007a).

The evaluation made a series of recommendations for schools and government agencies to help improve the sexuality education programmes. The recommendations for schools included developing guidelines for the teaching of sexuality education, assessing students learning more effectively, providing an learning environment that supports sexuality education, provide access to support services and regularly review sexuality education resources (Education Review Office, 2007a). For government agencies the recommendations were focused on providing resources and best-practice evidence for schools to use in developing their sexuality education curriculum (Education Review Office, 2007a).

As a companion to the evaluation, ERO also released a best practice guide which was designed to "help schools review their sexuality education programme" (Education Review Office, 2007b, p. 50). The report used examples of schools that had rated highly in their evaluation and while acknowledging every school has a different set of needs, there were some shared characteristics in those schools with highly effective sexuality education programmes.

\section{Each school had:}

- acknowledged the strong student need for being taught potentially awkward sexuality topics by approachable, trustworthy and empathetic teachers;

- organised their sexuality education programme with a strong focus on positive relationships and the emotional and social aspects of sexuality;

- supported their teachers in developing an effective sexuality education programme that was interactive and student-centred; - undertaken, or was in the process of completing, a regular school-wide review of the sexuality education programme; 
- ensured teachers had the opportunity for professional development, specifically in sexuality education, to establish high quality pedagogical knowledge;

- fostered a school-wide ethos of respect and a classroom environment of safety and inclusiveness;

- provided supporting pastoral care networks and medical services;

- communicated effectively in a variety of ways with the school community and parents;

- monitored the programmes delivered by the outside organisations;

- provided plentiful and varied resources which were updated regularly;

- collected and analysed school-wide student achievement information in sexuality education to plan for students' needs; and

- encouraged teachers to provide for the needs of diverse groups of students. (Education Review Office, 2007b, p. 76)

Allen (2011), completed a comprehensive research project focused on understanding secondary school students' views and experiences of sexuality education. 1180 students from all over New Zealand completed a survey which was followed by 10 focus groups, conducted in order to gain a deeper understanding of the information gained from the survey. From a teaching perspective, students were not so much concerned with who the person was rather that ''being knowledgeable', 'able to relate to young people' and demonstrating characteristics relating to a sense of 'professionalism' were imperative" (Allen, 2011, p. 131).

The evidence presented shows that the characteristics of highly effective sexuality education programmes focus on creating an inclusive school environment that recognises sexuality education as an important topic. Teachers need to be supported to confidently deliver the curriculum, a notion 
which is supported by students. In turn, successful sexuality education programmes should affect a reduction in young people's risky behaviour.

\section{Creating a structure for behaviour change - theoretical models}

Changing behaviour is a complex process for which there are a number of theoretical models. These models attempt to break down the steps to behaviour change in a population group and then design interventions to target each step in the change process. Glanz, Rimer \& Viswanath (2008) found in a review of 104 intervention studies for changing health behaviour and health education, three cognitive psychology theories were most dominant in the literature, they are: the Transtheoretical Model (TTM), the Health Belief Model (HBM) and Social Cognitive Theory (SCT).

\section{Transtheoretical Stages of Change}

The Transtheoretical Stages of Change model posits six steps to behaviour change, with each step requiring a different approach to achieve success. This model has proven useful when attempting to change health behaviour in populations for smoking cessation (Prochaska \& Velicer, 1997).

The model has six steps which people follow in making changes about behaviours:

- Precontemplation - not intending to take action

- Contemplation - intending to change in the next 6 months

- Preparation - taking action in the immediate future

- Action - taking specific attempts to change behaviour

- Maintenance - working to prevent relapse

- Termination - zero temptation to return to the old behaviour (Prochaska \& Velicer, 1997)

These six steps create a linear picture of change. While it provides a breakdown for targeting different stages of an intervention it is important to note they are not discrete and that people are unlikely to fit neatly into each stage as it happens, rather they move through as individuals. 
In terms of sexual and reproductive health in New Zealand, currently resources are targeting the precontemplation and contemplation stages of the process, which is increasing people's knowledge base and understanding of a topic. However, if we were effectively changing behaviour then there should be a noticeable reduction in STIs and unplanned pregnancy. Research from Taiwan focusing on contraception for post-partum women showed those who received transtheoretical based interventions "had significantly greater contraceptive self-efficacy and were more likely to choose more effective contraceptive methods at 2 months postpartum than women in the routine teaching and interactive pamphlet-only groups" (Lee, Tsai, Tsou, \& Chen, 2011 , p. 48). This research suggests that the transtheoretical stages of change model potentially has a place in the sexual and reproductive health area.

\section{The Health Belief Model}

The Health Belief Model (HBM) was developed in the 1950s to understand "the widespread failure of people to accept disease preventives or screening tests for the early detection of asymptomatic disease" (Rosenstock I. M., 1974, as cited in Janz \& Becker, 1984, p. 2). The original HBM was based upon three factors,

Health-related action depends upon the simultaneous occurrence of three classes of factors:

(1) The existence of sufficient motivation (or health concern) to make health issues salient or relevant.

(2) The belief that one is susceptible (vulnerable) to a serious health problem or to the sequelae of that illness or condition. This is often termed perceived threat.

(3) The belief that following a particular health recommendation would be beneficial in reducing the perceived threat, and at a subjectively-acceptable cost. Cost refers to perceived barriers that must be overcome in order to follow the health recommendation; it includes, 
but is not restricted to, financial outlays. (Rosenstock, Strecher, \& Becker, 1988, p. 177)

The HBM is focused on what external and internal factors need to be present for a person to engage in screening or protective health behaviours and how likely they think they are to get sick in the first place. A person's belief about sickness and health can be affected by a number of external factors. To take this into account the model also considers "diverse demographic, sociopsychological, and structural variables might, in any given instance, affect the individual's perception and thus indirectly influence health-related behavior" (Janz \& Becker, 1984, p. 3).

Research has shown the factors in the HBM can be useful in predicting risky behaviours, including whether young people will use condoms (Laraque, McLean, Brown-Peterside, Ashton, \& Diamond, 1997). By understanding risk taking through the lens of the HBM, interventions can be targeted and the three classes of factors which influence preventative behaviours. In a 2009 qualitative study focusing on the use of condoms during casual sex, the authors concluded the HBM "can serve as a useful framework for understanding sexual risk taking during hooking up, and offers suggestions for sexual risk-prevention programs on college campuses" (Downing-Matibag \& Geisinger, 2009, p. 1196). There could be a place for the HBM in sexuality education, especially for messages about the importance of participating in regular STI checks.

\section{Social Cognitive Theory}

Social Cognitive Theory (SCT) was developed by psychologist Albert Bandura. Its primary focus is on a person's self-efficacy and how that can affect their health outcomes.

Efficacy belief is a major basis of action. Unless people believe they can produce desired effects by their actions, they have little incentive to act or to persevere in the face of difficulties and setbacks. Whatever else may serve as motivators, they must be 
founded on the belief that one has the power to produce desired changes by one's actions. (Bandura, 1998, p. 3)

Like the HBM and the Transtheoretical stages of change, aspects of SCT have been shown to be useful in sexual health interventions (Glanz \& Bishop, 2010). SCT may be a useful tool in sexuality education as teachers could aim to increase "self-efficacy using three types of strategies (a) setting small, incremental and achievable goals; (b) using formalized behavioural contracting to establish goals and specify rewards; and (c) monitoring and reinforcement" (Glanz \& Bishop, 2010, p. 403). A 2009 Cochrane Review of theory-based interventions for contraception found that in three of the five trials based on SCT, "the treatment group had fewer second births, more contraceptive use (other than condoms), and more reported condom use" (Lopez, Tolley, Grimes, \& Chen-Mok, 2011, p. 14).

\section{Behaviour change in action: Uganda and HIV/AIDS}

The HIV/AIDS epidemic hit Africa in the early 1980s. By 1988 Uganda had the highest infection rate in the entire continent; however by 2001 these figures had halved (Kirby \& Halperin, 2008). This incredible turn around is attributed in most part to a country wide campaign, directed by the President, to change sexual behaviour in order to slow the growth of the epidemic. (Kirby \& Halperin, 2008)

The success of this programme was reliant on two aspects; the easy to understand, clear messages about the link between sexual behaviour and HIV/AIDS and the unified commitment of all agencies to reducing its spread. This kind of approach comes from grass roots/up as well as government/top down. The key factors were education and training, the involvement of international organisations, the empowerment of women to say no and a reduction in the stigma for those living with HIV/AIDS (Kirby, 2008).

There were three key behaviour change messages delivered to the Ugandan people by all organisations working to reduce the spread of HIV/AIDS: 
- Abstain from sex - The safest way not to get HIV/AIDS is to not have sex. Young people were encouraged to abstain from sex until they were married.

- Be faithful in long-term relationships - This was marketed using the 'zero grazing' metaphor, which depicted an animal tethered by a farmer in its own backyard and not able to stray into the neighbours yard. This was symbolic of those in long term relationships needing to be faithful.

- Use Condoms - Once condoms were widely available in Uganda they were encouraged to be used by people who were going to have sex outside of marriage or have multiple partners. (Kirby, 2008)

This campaign took the HIV rate in Uganda from 23\% total population in 1992 to around 13\% in 2000 (Baryarama et al., 2004). Uganda is considered the great success story for controlling an HIV/AIDS epidemic, so what can we learn from Uganda to apply to broader sexual and reproductive health education in New Zealand?

\section{Behaviours that reduce STIs and unwanted pregnancy}

Using the knowledge gained from the Ugandan HIV/AIDS crisis Kirby (2010) identified nine behaviours that needed to be addressed in order to reduce the number of unwanted pregnancies and the transmission of STIs that are relevant to a more Western context;

- Delay/abstain from sex - the only way to completely avoid unwanted pregnancy and STIs is to not have sex at all

- Decrease frequency of sex - if you are going to have sex, have it less often.

- Reduce number of sexual partners - Less sexual partners means less risk

- Avoid concurrent partners or partners with concurrent partners - having concurrent partners greatly increases the likelihood of STI transmission (Kretzschmar \& Morris, 1996),

- Increase time gap between sexual partners - if you are changing partners, consider increasing the length of time between them 
- Use a condom consistently and correctly - Condoms are only effective in preventing STIs and pregnancy if they are used correctly every time someone has sex

- Use contraception consistently and correctly - Hormonal contraceptives such as the oral contraceptive pill need to be taken regularly to be effective in preventing pregnancy.

- Be tested and treated for STDs - regular screening for both men and women is important. The most common STIs, Chlamydia and Gonorrhoea are easily treated with a short course of antibiotics (Auckland Sexual Health Service). As many STIs are asymptomatic, being screened regularly stops unwitting transmission (Auckland Sexual Health Service).

- Be vaccinated - The Gardasil ${ }^{\circ}$ vaccine for HPV was introduced to New Zealand in 2009 for women only for the prevention of cervical cancer (Clifford, et al., 2003). Evidence also suggests that it would also be beneficial to men as HPV has been linked to anal and oral cancers (Giuliano et al., 2011; Goldstone \& Moshier, 2010).

Kirby also points out at that while all nine behaviours are important from health/disease prevention perspective, if we are to package them into an education programme, they need not be explored separately. The simplest way to package these is through an ABC approach like Uganda, but in a relevant context for New Zealand young people.

\section{A - Abstaining is the safest form of contraception}

B - Before you have sex, $\mathrm{Be}$ at least $18, \mathrm{Be}$ in a mutually caring, loving and faithful relationship for at least 3 months, Be tested and treated for STIs, Be vaccinated against STIs, Be protected against pregnancy (use contraception), Be sure it is what you want (Voluntary, not pressured, consistent with your values). 
C - Condoms, Use condoms consistently and correctly every time you have sex (Kirby, 2010).

Kirby argues these three core messages can be the basis of topics for teaching about sexual health in ways that are relevant to young people (Kirby, 2010). In New Zealand, the legal age of sexual consent is 16 years (Kiwi Families, 2007), so while it might feel like suggesting people wait until they are 18 is appropriate, the legal reality and social norm needs to be taken into account.

While this approach is helpful in understanding the kinds of things young people can do to reduce the likelihood of STIs or unintended pregnancy the curriculum also needs to focus on relationships and social dynamics. Learning about STI infection transmission with concurrent partners is relevant and important information however; these messages don't seem to be making a difference in the health statistics. While the ' $\mathrm{B}$ ' includes be mutually caring, be loving and faithful relationship for at least 3 months and be sure it is what you want (voluntary, not pressured, consistent with your values), these are exactly the messages that are most difficult to convey to young people. The complicated nature of negotiating sexual safety with partners, relationship types and the influence of alcohol and other drugs on decision making in the 'heat of the moment' are often not developed well into adulthood. The behaviour change messages are always important however, further work needs to be done on exploring the psychosocial factors which are the less clear cut aspects of why young people continue to have unprotected sex despite seemly knowing the dangers.

\section{Summary}

Young women are not born with a fully developed sexual identity, nor do they create it in a vacuum. There are a number of factors that influence the way they develop and their subsequent behaviour. While the biological processes of development cannot be altered, many of the social and cultural aspects of development that affect behaviours (and the likelihood of a young woman having casual sex without condoms) are amenable to change. Consideration 
should be given to the role of alcohol, social constructions of female sexuality and the protective role that communication with parents can have.

Sexuality education varies hugely worldwide and is often driven by political forces such as the focus on abstinence education in the United States. For New Zealand, there is considerable diversity between schools and an Education Review Office evaluation found that in general schools are not meeting expectations. New Zealand can learn a lot from studying education campaigns that have affected positive change, such as the HIV/AIDS work in Uganda. Using some of the same basic principles as Uganda could help New Zealand to decrease its high rates of STIs and unplanned pregnancy. 


\section{Chapter Three: Research Approach and Methods}

\section{Introduction}

This chapter describes and explains the chosen research approach, including the theoretical framework, and the methods used. It will begin with a description of the underlying qualitative approach, Heideggerian phenomenology, and why it is a relevant and appropriate research framework for this topic. The chapter will then discuss the ethics, sampling techniques, participants and interview procedure. The final section focuses on the analysis and the rigour of the study.

\section{Research Approach}

The questions this research attempts to answer lend themselves to a qualitative approach. Qualitative inquiry is about creating an "understanding of the context, the consequences/outcomes, and even the significance of what is investigated in the larger world" (Wertz et al., 2011, p. 2). Specifically, this research is focused on the lived experience, and understanding how those factors have shaped young women's behaviours. To elicit that information this research will utilise the methodological approach of Heideggerain phenomenology.

\section{Heideggerian Phenomenology}

Phenomenology was originally born out of work by philosopher Edmund Husserl and is rooted in interpretivism. Phenomenology is described as "carefully, and thoroughly capturing and describing how people experience some phenomenon - how they perceive it, describe it, feel about it, judge it, remember it, make sense of it and talk about it with others" (Wertz, et al., 2011 p. 104). Researchers use phenomenology as a way to "study the conscious experience that would enable science to overcome the limitations of objectivism" (Wertz, et al., 2011 p. 52).

Martin Heidegger, a student of Husserl's, expanded the traditional phenomenological thought towards the lived experience or the notion of 
'being', which Heidegger calls Dasein. The translation of Dasein is "there being", which is interpreted as a person existing as themselves but also within a shared understanding of the world (Pascal, 2010). Traditional phenomenological approaches require the researcher to engage in 'bracketing'. "Bracketing' is the process of setting aside the researchers preassumptions or preconceptions and attempt to remain neutral (Crotty, 1998). Heidegger's view of the interconnectedness of the world and the being meant he felt it was impossible to truly bracket. He felt a researcher could not disconnect from their own world as "every encounter involves an interpretation influenced by an individual's background or historicality" (Laverty, 2003, p. 24) Instead, Heidegger's framework "permits and encourages the exploration and inclusion of preconceptions as legitimate components of the research" (McConnell-Henry, Chapman, \& Francis, 2009 , p. 3).

The researcher can and should acknowledge and explore their biases and experiences. By acknowledging bias, the researcher is able to recognise what is the participant's experience and what is their own experience. Through this, the researcher and participants co-construct a shared understanding of the event through discussion and exploration (Byrne, 2001).

\section{Phenomenology and sexuality}

This research is focused on the act of having casual sex without using condoms. However, it is also seeking to understand why women put themselves at risk of pregnancy and STIs. This research fits naturally with Heideggerian phenomenology as it is focused on the idea of the women's decision to have sex being more than their individual decision but also tied into their social and cultural context. The ideas an individual holds about sex and sexuality are deeply imbedded in their understanding of the society they live in. For Heidegger this was called 'being in time', reflecting the idea that our being is always changing, learning and growing all within the context of our world (Pascal, 2010).

This notion of 'being in time' fits with not only our learning about our sexual selves over time, but also the physical changes the human body goes through 
as we age. Puberty in the early teens, complete frontal lobe development in the mid-twenties through to the menopause for women in their fifties are all fixed points in human development and signify changes in our being and life context.

\section{Sample}

Eleven women were recruited for the study using a mixture of recruitment via posters $(n=6)$, snowball sampling $(n=2)$ and through personal networks $(n=3)$. Posters were displayed in various public areas of Victoria University, the Wellington Regional Hospital and Family Planning's Margaret Sparrow clinic in central Wellington (See Appendix A: Poster). The poster invited participants to call, text or email to register their interest in the study. They were then forwarded a pre-screening email to ascertain their acceptability for the interview which included their comfort with talking about their own experiences of casual sex. The pre-screen also ensured they fitted the inclusion criteria which were:

- female

- aged between 18-25 years old

- had at least one experience of casual sex with a male

\section{Sampling Rationale}

While the inclusion of young men in the sample was considered there were two main reasons for choosing women only.

1. This is a small qualitative study; to explore these issues fully with both men and women would be a larger scope than is possible in a Masters thesis.

2. Decision making around pregnancy termination or continuation tends to fall to women. The research wanted to be able to explore the idea of pregnancy 'risk' from a woman's perspective.

The sample was also not limited to heterosexual females. Lesbian and bisexual identified women were welcome to participate provided they had experience of causal sex with a man. This was again to ensure that the 
interviewer could discuss both the issue of pregnancy and the STI risk. None of the women interviewed identified as lesbian or bisexual during the interviews, however they were not directly asked.

\section{Participants}

The women interviewed were asked to provide some basic demographic data about themselves. This data further informs the notion of context for these particular women and is summarised in Table 1.

Table 1: Demographic Profile of Participants

\begin{tabular}{|l|l|l|}
\hline & $\mathrm{n}$ & $\%$ \\
\hline Ethnicity & 2 & 18 \\
- Maori & 6 & 55 \\
- NZ European & 3 & 27 \\
\hline Employment Status & & \\
- Tertiary Education only & 5 & 45 \\
- Tertiary Education and Work & 3 & 27 \\
- Full Time Work & 3 & 27 \\
\hline Highest Qualification & & \\
- Bursary or NCEA Level 3 & 5 & 45 \\
- Some Tertiary or Polytech & 2 & 18 \\
- Tertiary Qualified & 4 & 36 \\
\hline Household Composition & & \\
- Live with Parents & 2 & 18 \\
- Live with Partner & 3 & 27 \\
- Live with Friends & 5 & 34 \\
- Live Alone & 1 & 9 \\
\hline
\end{tabular}

As a requirement of the study, all of the women were aged between 18 and 25. They were predominately New Zealand European and where more than one ethnicity was selected the 'ever Maori' prioritisation was used making Maori their primary ethnicity (Cormack \& Harris, 2009). All the women were 
either already tertiary qualified $(n=4)$ or currently in tertiary education $(n=7)$. It is likely that this reflects the placement of the advertising posters. Nine of the participants were from the greater Wellington region and two were based in Hawkes Bay. Five women lived in flatting situations with friends while the remainder lived with their parents $(n=2)$, partners $(n=3)$ or alone $(n=1)$.

\section{Interview Procedure}

Interviews were chosen as the primary method of data collection as they "allow us to enter the person's perspective" (Patton, 2002, p. 341). The interviews were conducted face-to-face using a semi-structured interview guide (See Appendix B: Interview Guide). A semi-structured approach allowed the interviewer the flexibility to let a conversation 'wander' as well as making sure key topic areas were covered. Patton (2002), describes the freedom of semi-structured interviews to "build a conversation within a particular subject area, to word questions spontaneously, and to establish conversational style but with the focus on a particular subject that has been predetermined" ( $p$. 343). In many cases, the participants began discussing a topic without prompting. Semi-structured interviews allowed the interviewer to continue with that line of conversation being directed by the participant.

The interview questions in the schedule formed two distinct parts. The first was focused on the experience(s) of casual sex and factors which encourage or discourage the use of condoms. For example "What circumstances do you think increase the likelihood of someone in your age group having casual sex?" The second part of the interview focused on their recollections of school based sexuality education and elicited ideas for how to improve those programmes. For example "Who do you think is responsible for delivering sexuality education?" Each question also had a series of possible probe questions in case the conversation stalled or the participant needed an example.

Six of the interviews were conducted in study rooms at the Victoria University library, the remaining five interviews were at either the researcher or participant's home. The interviews lasted an average of 50 minutes each and 
were digitally recorded using a Sony Digital Voice Recorder. Each recording was downloaded onto the researcher's computer and then copied to a portable memory stick for transcription. The interviews were transcribed verbatim (minus utterance) by an independent transcription service.

\section{Analysis}

It was decided after eleven interviews that a point of saturation had been reached with no new information being presented. The initial stage of analysis involved the researcher listening to the interviews while reading through the transcripts to become immersed in the data. The transcriptions were imported into the software package NVivo (QSR International Ltd, 2009) as a way of organising the data however the coding was done manually. The interviews were first coding for broad themes which emerged from an initial reading and analysis of the transcripts. These were discussed and tested with the researcher's supervisor for agreement. Re-listening to the interviews allowed clarifications to be made of tone nuance which is not available when reading a transcript.

Once the broad themes were decided, the second stage of analysis began using the hermeneutic circle, which is an important aspect of Heideggerian phenomenology. The hermeneutic circle illustrates the importance of shifting focus between both the parts of an experience and the whole so the social and personal context of an experience is understood (Laverty, 2003). In the context of this research, the interviewer and participants moved between specific events and overall life context, so as to understand how one might affect the other. During the secondary analysis phase, this technique was again employed but switching between line by line analyses to a whole passage of text. By switching between the detail and the whole, the researcher was able to keep the broader context in my mind while analysing the data at a detail level. 


\section{Ethical Considerations}

Ethical approval was granted by the Victoria University of Wellington Faculty of Education Ethics Committee (REF: SEPI/2010/111: RM 18186) on the $3^{\text {rd }}$ of February 2011.

Sex and sexuality are very personal topics and great care was taken along the journey from recruitment to interview completion to ensure the women were comfortable with the study. As a part of the pre-screening email, the women were asked directly if they would be comfortable discussing their own experiences of casual sex.

Prior to the interviews, participants were given an information sheet (see Appendix C: Information Sheet) which contained a summary of the study and a list of phone numbers for counselling services and other resources such as Healthline. They were also provided the web address for Family Planning Association as a resource for information on sexual health.

At the interview the women were again asked if they were comfortable discussing their experiences of casual sex. If they agreed they were asked to sign a consent form (see Appendix D: Consent Form) which included their agreement for the interviews to be recorded. All consents forms, recordings and interview transcripts have been securely stored at the researcher's home in a lockable filing cabinet and any electronic versions or information are stored on password protected computers.

\section{Rigour}

Qualitative research is about people, and while these approaches give rich, deep data they are often faulted for having no simple way to test the reliability and validity of the findings (Patton, 2002). During this process the researcher employed a number of methods to increase the rigour of the findings.

The first strategy was to use Heideggerian phenomenology as an underlying conceptual framework. This method allows the researcher to consider their 
own biases and experiences of the topic. By thinking through these issues prior to starting, the researcher was able to position themselves within the research and be aware of pre-existing biases. The researcher also stated very clearly to the participants at the beginning of each interview that no personal judgements were held of their behaviour.

Where possible, the researcher employed techniques to triangulate the data. Firstly, the use of a semi-structured interview schedule gave a series of reminders to ensure the same questions were asked to everyone. Patton (2002) describes using a interview schedule as "more systematic and comprehensive by delimited in advance the issues to be explored" (p. 343).

During the interviews, where necessary, participants were asked to confirm that the interviewer understood their statements. This was done by using questions such as, "I just want to check that you mean..." This way the interviewer was able to continually check understanding with the participants and be sure the data being collected was robust. During the coding of the first broad themes, a series of discussions were held between the researcher and supervisor as a way of triangulating the analysis that was taking place (Patton, 2002). This support allowed space to test ideas and thinking at the start of the analysis process. By doing this there was also an opportunity to talk through ambiguity in the data and further consider personal biases.

Where possible and necessary, respondent validation (Merriam, 2009) was utilised. All participants were invited to add any additional thoughts via email if they wished and were encouraged in cases where they lost a train of thought during the interview. In two cases this was done spontaneously by the participants who contacted the interviewer themselves to provide clarification and further comment. These participants had continued to think about the interview afterwards and wanted to add some more thoughts to their answers. In both these cases, emails were exchanged to ensure full understanding of the extra information they were providing. 
In one other case, the researcher approached the participant to gain clarification on a particular passage of the interview to ensure the meaning was fully understood. During the initial analysis there was some ambiguity which was not resolved by listening to the interview again itself. The participant was approached to clarify the meaning of a statement through email. In each of the three cases the extra data was added to the analysis.

\section{Summary}

The study is rooted in understanding the lived experience. It uses Heideggerian phenomenology to understand to the way the women's experiences have shaped their consequent behaviours with the hermeneutic circle utilised during the analysis phase. The participants were drawn from universities, sexual health clinics and personal networks with interviews as the primary form of data collection. The ethics of the study were approved by the Victoria University of Wellington Faculty of Education Ethics Committee and care was taken to ensure the rigour of the findings. 


\section{Chapter Four: Findings}

\section{Introduction}

This chapter is structured around the seven key themes which emerged from the analysis: alcohol, relationships and pressure, feeling powerful and powerless, information about sex sought outside of school, taking risks and protecting their health, the role of men and education. Each theme has a series of key subthemes which emerged during the secondary analysis aided by the hermeneutic circle.

\section{Alcohol}

"at the same time, they're experimenting with sex, they're experimenting with alcohol, and they don't know their limits with either - it's about needing those consequences, so you know how far you can take each one".

The women interviewed identified strongly with the notion that New Zealand has a binge-drinking 'culture'. The 'culture' was described in different ways, but with the general feeling that wider society expected them to not only drink, but also that "it's alright for me to go out and drink 12 standards drinks in one night". They reported feeling that drinking was the norm and thus became active participants in that 'culture'. The participants expressed that in New Zealand, drinking alcohol is seen as an activity in and of itself, and that prior to being 18 years old, they had no trouble obtaining alcohol from parents, or often older boys. This normalisation of alcohol as part of a young woman's social life meant they began to view it as necessary in social interactions, particularly when meeting or talking with men saying - "I think New Zealanders don't have the guts to even talk to the opposite sex without alcohol in them". The effect that alcohol has as a substance led the women to act in different ways, or feel less inhibited, which was seen as a positive with many women reporting that they drink to get to get rid of their inhibitions. Most of the participants acknowledged that their drinking habits changed as they got older; however this seemed to be related to the increased responsibilities of adult life. The women in the sample who were working full time no longer felt 
able, or wanted to be out all night drinking, "we're not actually going out and hitting the piss hard [now]".

\section{Alcohol and Sex}

When participants were asked to identify a reason for New Zealand's poor statistics for STIs and unplanned pregnancy, they all stated alcohol would be a major factor because "not a lot of people have casual sex when they're sober". There was unanimous agreement that drinking and casual sex go hand in hand; however, it was not always clear which came first. When asked directly, the women seemed unsure if drinking led to casual sex or, if they wanted to have casual sex, drinking helped them reach that goal. Alcohol made it easier to talk to the opposite sex, especially if they were strangers, and they felt their sexual inhibitions and body image issues also lowered. Given that drinking alcohol leads to a lowering of inhibitions, these women may have been using alcohol as a bridge to having sex, which they then could, and would, blame for their behaviour. There was one participant however, who did not drink alcohol but did have unprotected casual sex. She even commented "even without the effects of alcohol clouding my judgement, I still went ahead and had unprotected sex with him".

The application of blame for having casual sex was a complex issue for women. In most cases, the women blamed alcohol for sleeping with someone they considered to be unattractive. Even though they felt it was not an excuse, they treated alcohol as an external cause that led to their behaviour - "you are quite willing to say yes to anything". Because of this they would go easier on themselves emotionally, for making what they considered to be bad decisions. This kind of retroactive application of blame on alcohol was common for women who engaged in casual sex while drinking. In some cases, however, they would drink which would then allow them to 'lower their standards'. It would seem that many of the women interviewed wanted to have sex but having done so they felt as though they had made a mistake. What was not clear was whether the women felt that having casual sex was the mistake, or them wanting to have sex and allowing it to happen was the mistake. It seems that participants might have wanted to distance themselves from the decisions 
they had made while drunk/drinking as it was at odds with their gender stereotype, which could have resulted in distancing themselves from their sexual desires. This externalising of alcohol as being the 'blame' for their behaviour offers an interesting insight into how these young women are constructing their sexual identities. While they want to have a feeling of strong sexual agency, which would allow them to satisfy their physical desires, they felt unable to balance this within their perceived gender stereotype.

\section{Alcohol and Contraception}

Participants commented extensively on the role they felt alcohol played in having unprotected sex. As with having casual sex in the first place, they externalised the blame for their not using condoms on alcohol. Although, many participants commented that while they did not use condoms, they were on some form of hormonal birth control. It was not until after having sex did they comment that they did not have any protection from STIs, realising "he could have had AIDS, and I didn't know".

Participants were often unprepared for casual sex in the first place, as they stated it was unplanned and opportunistic, and they were not carrying condoms. This lack of preparation seems to be related to the women not wanting to be judged for wanting to have sex. There was a perception that if they carried condoms they must be promiscuous, which is again is a reflection of the way society constructs femininity. Rather than working against it, the participants were complicit in the stereotype and often worried about what people might think of them if they had condoms, even strangers - "I just always think of myself at the dairy, when I'm opening up my wallet to get out my card, they can see it, and l'd be humiliated".

A secondary method that participants used to mediate their regret for not using condoms when they were drinking was thinking they could tell if a man had an STI just by looking at him. Many of the women in this sample seemed quite convinced they would be able to tell if someone had an STI. Again, this idea of a man being clean was assigned retrospectively and seemed to be more of way for the women to placate their own concerns. When probed they 
admitted that in reality they knew they couldn't tell, but they still assumed there would be an outward marker, "you always expect certain types of people to have them....and I would never sleep with those types of people, so I would never get anything". In one case however, a participant reported seeing a lump on a man's penis and thinking she shouldn't have unprotected sex with him but did anyway. She felt a huge amount of regret for that but had no explanation as to why she did it.

There were a few women, however, who were insistent on using condoms when having casual sex, even if they were out in town drinking and they were not sure why other women did not. These women, who used condoms every time during casual sex, did not perceive any barrier to getting condoms any time of the day or night. Interestingly, these were also the women who did not feel regret after having causal sex or 'beat themselves up'. They saw it as a way to have their physical needs met without having to have a relationship, saying "I don't want to call him the next day either".

\section{Relationships and Pressure}

"I know a girl that went with a guy and came back crying, 'cause she... 'cause he just had sex and that was it, there wasn't more afterwards - so, come on, you were doing that in an alleyway, you can't expect him to want to get married from that?"

All the women in the sample commented on the pressure to have sex or how to act in sexual situations. For most women, this included some level of peer pressure, be that overtly or not. For others, there was perceived pressure from their sexual partners. However, all of the women applied pressure on themselves. This internal pressure was focused on making sure they were behaving 'normally' and often led to the women behaving in ways they later regretted. This confusion was caused by contradictory behaviour messages for what society, men and their peer group deemed to be normal. For many of the participants, the downstream effect was low self esteem and being unsure of how to assert themselves in sexual situations. 


\section{Peer Pressure}

Participants noted that the nature of peer pressure changes as you age. The women stated that when they were in high school, there was a perception that everyone was having sex, even though, upon reflection, the women felt it was most likely untrue. The perception that 'everyone else was doing it' lead some women to interpret that "people have sex or say they're having sex to be grown up" and this was a good thing. Around high school age, the women wanted to seem older than they were. When they recalled their high school experiences, the women noted that the kinds of parties that were thrown were very much about drinking and "sex was just there". With the addition of alcohol and peer pressure in a party type atmosphere, the women didn't seem to know how to act. While some told anecdotes of turning boys down at these events, they often didn't tell their friends about it for fear of being judged. Peer pressure in teenage years seems to encompass not just the initiating of sex, but also the who, when and where people do it. Some participants felt pressured to have sex while they were at parties, as if it was normal to find an empty room and have casual sex. For a younger girl struggling to find her voice/power in sexual situations (or sexual agency), this would be a very conflicting and confusing situation to navigate.

As participants aged, the nature of the pressure they felt from friends changed and mostly stopped. Most surmised this was because their friend groups had changed from one of convenience at high school, to wanting to spend time with people in wider society. They were more likely to discuss their sex life openly and be less judgmental of each other "because you talk to your friends about casual sex...everyone shares their experiences with each other". This type of group talk was used to affirm decisions they had made in partners but also still to gauge what was considered 'normal'. For some women there was still a feeling that if they didn't or weren't having sex "all my friends would think I was crazy".

\section{Partner Pressure}

Most of the overt pressure referred to by the women related to men wanting them to have sex without condoms as men told them it felt better without 
them. Men also seemed unconcerned with STIs and assumed if a woman was using another method of birth control then condoms weren't necessary. This was highlighted by one participant who wanted to use condoms because she had an STI and didn't want to pass it on and her partner stated directly. He stated directly, "I don't care". This active avoidance of condoms by men was confusing for many of the women who then were not sure how to be insistent, especially during casual sex where there was less intimacy and room for conversations about safety. Conversely, the women also talked of some men who were insistent on using condoms at all times, referring to them as the "good guys".

Some of the women interviewed had experienced men actively trying to talk them out of using condoms, which in most cases they ultimately agreed. The women spoke of feeling like they were leading the guys on and "I almost feel like it shouldn't have got to that stage if I didn't want to do it". While these women knew they shouldn't have unprotected sex, and didn't really want to, they often allowed it to go ahead anyway because they felt it was their 'obligation' to do so. When asked to explain where they got that idea from, they where unable to pinpoint a specific time. Once again, the women were behaving in ways that contradicted what they knew was a good idea, because they felt some expectation to play the role they thought matched their gender.

While almost all of the women in the sample stated they would not be swayed by a man who attempted to pressure them into having sex without a condom now, they had all done it in the past. Once again, the women commented on feeling as though they were more in control of themselves and had more confidence in all sexual situations.

\section{Internal Pressure and the Emotional Ramifications of Sex}

Many of the women interviewed stated they felt emotionally unprepared to have sex for the first time. This was true of sex generally, but particularly when it came to their first casual sex experience. The participants stated over and over again how they had no preparation for how to feel about themselves after sex and they were quite overwhelmed with a series of complex 
emotions. This seemed even more of an issue to them if they had been drinking alcohol and had started having casual sex, "they don't tell you how to make new friends, or sleeping with someone at the party you're going to, and what do you do when you wake up next morning and you want to run straight back to your dorm room".

Participants also stated that no one had told them how to pick someone to have casual sex with, or how you might get yourself out of a situation you didn't like. This reflected a general lack of emotional preparedness which seemed to be worse when they engaged in casual sex, "the whole goodbye thing in the morning, maybe l'll call him back, maybe I want to see him again maybe I don't'. The participants' sexual histories seemed to be filled with trial and error attempts at understanding their sexual selves which often led to considerable amounts of regret. In feeling regret, the women often turned the blame back on themselves, countering "it took me a good six weeks to recover, and the only way I could deal with it was to say ok, lesson learned".

The participants commented at length about their belief of a man's ability to detach his feelings from sex. Many of them have had the experience of feeling heart broken when a man wasn't interested in them for more than casual sex saying "I realised he was never really interested in me". As a part of understanding adult relationships, it took time for the women to learn that sex itself wasn't a relationship which was particularly true in casual situations. Again, a few women were able, liked they perceived men do; to 'switch-off' the emotional side of sex and view it as a purely physical act which they were active participants in. However, this is something that they commented they were only able to do once they were older. This seemed to signal a change for the women in terms of gaining some sexual agency. This means they were less likely to express regret at having casual sex as they felt they owned the decision to have casual sex purely for pleasure.

\section{The Making of Sluts}

There was an almost universal struggle, across the women interviewed, about carrying condoms and their fear of being thought of as sluts. In some cases 
they stated while they would confide in their friends, they did worry how strangers might judge them if they found out, "I just always think of myself at the dairy, when l'm opening up my wallet to get out my card, they can see it, and l'd be humiliated". This concern was based around their fear of being thought of as a slut, a term used negatively to describe a woman who is perceived to have a lot of sex. Interestingly the women didn't seem to have any one definition of what actually made someone a slut and seemed to apply the title differently in different situations. However there was an almost universal consensus that other people would perceive you as a slut if they see/know you are carrying condoms. It seems that carrying condoms meant you must want to, or be out looking for, sex which is at odds with the social perception that women should be both chaste and chased.

There was a definite correlation between being perceived as a slut and having casual sex. However, if a girl had a number of 'boyfriends' who she has sex with that was ok, but having sex with the same number of men casually wasn't because "it seems more acceptable, even if it's the same number". The same was said if a woman had an STI, which participants commented was very unfair given a woman could get an STI from having sex once. Despite being unable to define it, the notion of being a slut, or acting in a slutty way was condemned by the participants. They reported that often within their peer groups they would tell someone if they thought their behaviour was becoming slutty. However, given that the women reported that their friends might think they had a problem if they weren't having sex, it seems unclear how they balanced the fine line between behaving 'normally' and behaving like a slut.

The participants commented they felt there was an unfair double standard in the way men and women were viewed in relation to "he's a stud, she's a slut". While a woman would be condemned for sleeping around it was considered by participants to be ok for men to sleep with a lot of women, and especially to have casual sex. This perceived social norm adds another layer to the pressure women feel to behave in certain ways. While they may want to have their physical needs met through casual sex, they risk being perceived as sluts for doing so while for men it is considered a normal and healthy thing. 
None of the women interviewed knew where these contradictory sexual expectations came from and despite hoping this stereotype would change they seemed unsure of how it ever would.

\section{Feeling powerful and powerless}

Almost all participants commented that women use sex as a tool to get what they want, at times approaching sex like a currency, usually to trade for a relationship. The women interviewed talked of using sex as a way to secure a boyfriend when they were younger, with the assumption being that if they had sex with a guy it would lead to a relationship "and they can entice men quite a lot by it". When the women were high school aged, having a boyfriend was seen as an important thing within peer groups, and often attributed to their status within the group. Sex also represented being an adult or feeling older which they also considered important as teenagers. Many of the women felt they wanted to hurry the process of growing up and felt that having sex would help them achieve that. In this way, the women were attempting to use sex to gain something, either a relationship, or a feeling of being older and more mature, "[I was] just living life as a 25-year-old".

The women had also seen many examples where girls "wanted to keep the boyfriend so they get pregnant". They described a situation where a boy was about to dump a girl and she didn't want him to so she would intentionally fall pregnant. However, in most situations the relationship ended anyway. For the girl in this scenario, she assumed that getting pregnant would keep a relationship going and so was using sex as a means to that end. It seems the most common consequence of having a baby and also having no boyfriend was not one they considered likely when deciding on this course of action. While these women thought they were starting from a position of power, they ended up powerless and often unprepared to deal with the decision they had made. While this situation was not one any of the women interviewed had experienced, they did feel sympathetic towards the girls it had happened to although unanimously agreed it wasn't a good choice. 
The women interviewed identified that sex was an integral part of a relationship and in some cases by having casual sex they were attempting to signal that they were available for one, with the exceptions being the few women who had casual sex purely for pleasure. One of the participants commented that New Zealand does not really have a 'dating' culture, so young people have no way of courting each other prior to actually starting a relationship. This lack of 'dating' may well lead to women to using sex as a power leverage to getting a man interested in a relationship. This mismatch of expectations tended to leave the woman feeling upset and confused when the guy was only ever interested in sex. Once again, women go into a sexual situation feeling they have the power and end up without it. This highlights another mismatch between what women want and how they act in order to gain it.

\section{Getting information about sex outside of school}

"Masturbation, I had no idea what that was until a magazine told me. I mean, it was never mentioned in school, so how would you learn it at school?"

There were a number of ways participants learned about sex and relationships and often they provided contradictory information. The most common places were from parents, friends, medical professionals, self research and the media. In each case there were positive and negative experiences.

\section{Parents}

The women interviewed seemed to fall into two opposing groups when it came to their parents and sex, they either talked about it directly or they did not talk about it at all. Some of the women had very open and honest relationships with their mothers especially. They reported being able to freely discuss not just issues to do with sex and contraception but also their relationships and feelings. These women felt as though they would be less likely to make bad choices when it came to having unprotected sex, but if they did they would have a way to deal with it without being judged. Many of the women in this group went to the doctor or Family Planning clinic with their 
mothers to get contraception and some of their mothers also offered to talk with the women's friends and partners. This open dialogue was based on trust and the women reported they felt safe discussing these issues with their mothers. While this may not have lead to a direct reduction in unsafe sex, the women were able to access help and support if and when they wanted it and felt less shame about sex generally.

The group of women who did not have an open dialogue with their parents tended to report more feelings of shame and would often ended up 'sneaking around' with boyfriends because they didn't want their parents to know. They felt they lacked an understanding of their bodies and what was happening to them at puberty and were unable to talk to their parents about it. The women attributed this to feeling uncomfortable talking with their parents about sex and assuming their parents would also find the conversation difficult. There is a possibility that their parents were waiting for the girls to bring the topic up rather than initiating it themselves. Some women were given books by their parents that were intended to explain puberty. Interestingly these were mostly left in their bedrooms without any discussion or explanation. Again, this was interpreted by the women as their parents distancing themselves from the conversation which made them feel as though they could not ask questions even if they wanted to. For some women, talking about contraception with their mothers came a long time after they had started having sex and they had accessed it themselves. It is difficult to interpret what the parents may have been thinking but the women attributed this to feeling as if their parents did not want them to grow up. This may be a genuine lack of understanding by their parents as to what their children are doing or conversely a 'head in the sand' type reaction. It's hard to know whether parents did not actually want to talk or as one participant noted, "it's probably a lot more awkward for them than it is for you".

In a minority of cases participants' parents also had strong religious beliefs, and they felt this greatly affected their views towards sex and sexuality. For these women, the sex talk consisted of "wait until you're married". One participant talked extensively about feelings of guilt about sex related to her 
religious upbringing and said that she felt she was given contradictory messages at home, school and church. For another participant, her involvement in religion meant that she ignored health class in school because she felt it did not apply to her. She also misinterpreted some aspects of her religion and assumed it meant she could not get things like cancer and STIs, "I felt like I was fairly invincible".

Some of the women who did not feel they could talk with their parents found other adults they felt they could confide in. In some cases it was an older sister and in one other an aunt who they considered to be different from their parents. This gave the women an adult figure who they trusted but kept a distance from their parents, who they didn't want knowing too much of their business.

\section{Friends}

Some women felt they accessed most of their information about sex from friends and this often led to misconceptions and false beliefs. In retrospect, the women identified that this information was not completely helpful because they had "really limited knowledge". Participants recalled fallacies or "urban legends' to do with sex that they had heard from their friends particularly when they were teenagers. For example, you cannot get pregnant if you have sex with the girl on top because of gravity. While they now laugh about that kind of comment, at the time they had no reason to believe that it was not true. Misconceptions about contraception and sex passed from peer to peer in this way can cause a great deal of confusion for young women. While they may not be inclined to believe the information that is being presented to them, they are very conscious of fitting into the group. In which case, passing the information along or believing some part of it could leave them in a vulnerable position. This highlights an area in which young people might make a wrong decision based on false information they gained from friends leaving them at risk of pregnancy and STIs.

In a few cases, the women relied on the older female siblings of their friends for information about sex and contraception. The perception was that the 
older sisters freely answered their questions and seemed to enjoy giving them the information they needed. However, it is not clear from the interviews how accurate these older sisters were. Given that they are likely to be only a few years older than the girls themselves, and probably still in high school, they may well have been the perpetrators of false information. Given the power dynamic and the impression that their older sister knew more by virtue of being older, the girls would be more likely to believe what they said. If the information was false, they would again be left in a vulnerable position.

\section{Medical Professionals}

Almost all of the women interviewed had sought the advice of a medical professional. There was a feeling that medical professionals could give them factual and honest advice about sex and contraception and they could trust the information more than any of their other sources because it was "more medical opinion, rather than a religious opinion".

Most women visited their local Family Planning clinic for contraception, STI checks and advice on sexual health matters. The women reported sometimes attending these clinics in groups with friends and found that the staff were friendly and straight up with them. The women found it comforting that the doctors and nurses had "been round the block a few times; they knew how shit worked, and they didn't give a damn". This feeling of anonymity was particularly appealing at a Family Planning clinic where they felt they wouldn't be judged because everyone was there for advice on sexual health. This was unlike their regular GP's office where they worried they might run into a friend of their parents or someone they know. Participants also felt that Family Planning was much better at relating to them, on their level. They felt comfortable in a way they wouldn't have with "the 40-something year-old male counsellor". In one case, a woman's mother suggested she go to Family Planning for sexual health advice because it was free, and she would have to pay to see her GP.

One participant commented it would have been good to have someone from Family Planning come to their school to talk to them about sexual health. This 
is a service that Family Planning offers but schools have to pay for it. It seems as though the women were responding to the atmosphere, level of comfort and openness they felt when attending a Family Planning clinic, which is an important lesson for any school based programmes.

Two of the women interviewed had careers as health professionals and had learnt a lot of new information about sexual health from their university level courses. While both of these women had accessed Family Planning for sexual health advice in the past, they both felt their specialised learning at university level uncovered a number of things that would have been helpful to have known earlier. This means despite being able to access advice and support from a number of places, young people may still be missing out on vital information about their sexual health.

\section{Self-education}

A few of the women self educated through books and the internet. In one case this was due to a lack of information being provided by parents and sheer curiosity. In two other cases it was after they had been diagnosed with a STI "so I educated myself" on what it meant. Interestingly, the other participants when asked directly said they didn't really do any self education on sex or sexual health. This may follow with women not really being concerned with STIs to begin with, if they don't see them as a real threat they won't be interested in educating themselves.

\section{Media Influences}

The overall influence of the media was difficult to tease out with the women interviewed. There were very few cases where the women felt as though any form of media had directly influenced their behaviour or feelings about their sexual health. The most commonly mentioned media were magazines such as Cosmopolitan, Dolly and Girlfriend. These magazines often contained a "sealed section", which had information about sex. Much of the information is intended to be educational but is couched as real life stories. The girls who had access to these magazines tended to get them from their, or friends' older sisters. The sealed sections were quite salacious and the participants 
reported learning things that were never discussed in school or anywhere else, "masturbation, I had no idea what that was until a magazine told me". In some cases the educational content of these magazines would be very useful to girls but they also contain a lot of information which could propagate a negative gender stereotype. Like all media, women need to be careful that they understand what they are reading both explicitly and implicitly. These magazines can also set up false expectations, particularly about sex, "then, when they come to experience it, they have not as enjoyable a time".

One woman touched on self-help type books as something she felt had positively influenced her understanding of sex and relationships. These books are designed to give the reader a deeper understanding of why people act the way they do in relationships. They are primarily aimed at adults although sections may be helpful for high school aged students. The participant commented she would have been able to understand some parts of the books if they were "watered down".

A few women also made mention of movies, such as Twilight as influencing them. However, again this was more about relationships and wanting their own boyfriends to be more like the characters in the movies. Some women did comment that if they had seen a story line on a TV programme, like Shortland Street, which featured an unplanned pregnancy or STIs, they would take notice. However, they would want it to show the whole process, rather than a character finding out she was pregnant, then going to the hospital and it all being over.

There was no mention of any movies or media giving them false information about sex or sexual health. While media may well have an impact on people's sexual behaviour, it seems to be more to do with gender stereotypes and expectations on relationships. As one participant commented these forms of media make people think "everyone will have their happily ever after".

\section{Taking risks and protecting their health}

"You kind of think you're bulletproof" 


\section{Risk Taking and Contraception}

The majority of participants said they did not really think about STIs, which is why they reported not using condoms even when they were having casual sex. This 'not thinking' happens in two ways, either the participants do not consider the likelihood of their partner having an STI, or simply, "had no thought whatsoever that I might get an STD". Their major concern was avoiding pregnancy, with STIs being an afterthought because, "say with Chlamydia, you can just get a pill and it goes away". When questioned further, the women seemed to hold a belief that most if not all STIs could be cured with a pill; therefore they were not really a big deal. One participant also extended this idea to include pregnancy and the use of the morning after pill. She felt comfortable using the morning after pill to ensure she did not get pregnant and in doing so thought having unprotected sex was not a problem. This is likely linked to the women's depth of knowledge of STIs. They most often mentioned Chlamydia as their example, which is a bacterial infection and can be cured with antibiotics. When STIs such as the Herpes virus were mentioned (for which the symptoms can be treated but the virus stays with you for life), the women spoke as if they considered themselves almost immune to getting STIs, "I just think I didn't think it would happen to me".

The other reason the women did not consider STIs was because "these people [men they are sleeping with] don't have STIs", although the women greatly underestimated the prevalence of common STIs. It seems that this was an extrapolation of not thinking about STIs in the first place. The women applied this retrospectively to more of a hope than a belief. They hoped that the men they had been sleeping with did not have an STI, but because they could not be sure realized afterwards they were really gambling. They admitted they knew they could not actually tell just by looking at someone if they had an STI but they still held an internal picture of what they thought an infected person would look like. Interestingly around a quarter of the women in the sample volunteered that they had either had an STI or unplanned pregnancy as a result of unprotected sex. Their relaxed attitude towards STIs meant some women were shocked to discover they had later contracted one. 
Their views about protection from STIs had changed as they had gotten older and they became more concerned with the potential effect on their fertility. Admitting this concern meant that they did know that STIs could affect their long term health, "I'm very lucky not to have an STI, I think, 'cause yeah, there have been times when l've been pretty irresponsible".

Deliberate risk taking with contraception was commonly discussed by participants. In these cases the women reported thinking deliberately about STIs, yet still chose not to use condoms. Nearly all of the participants had a sexual experience where they had considered condoms and then decided not to worry about it. There were several reasons for this, they were on other kinds of contraception (pill etc), they did not want to ruin the 'moment', or they would fix it afterwards. One participant commented it was easier to worry about fixing it afterwards than using a condom at the time. She took the attitude that she would most likely have a check up after casual sex, so any issue could be dealt with then. However, she maintained that she would not get anything because "with pregnancy and STIs, you always expect certain types of people to have them, but...I would never sleep with those types of people, so I would never get anything". In one other case a participant knew that her partner had an STI, after seeing a wart on his penis, and still chose to have unprotected sex with him.

Not wanting to ruin 'the moment' was cited as a factor by many of the women to explain why they didn't stop to use condoms. Despite knowing that they were having sex with a stranger and STIs could be an issue, they felt they did not want to interrupt the sex to suggest condoms. It would seem that this has more to do with the women not being able to assert themselves than with actually really enjoying the sex they were having, "I was kind of thinking oh, well, you're lucky to be getting this anyway, you know". Most of the women later regretted having casual sex and not using a condom especially as they thought about it at the time. The few women who felt able to assert themselves in sexual situations do not have unprotected sex because "that reward is never worth the risk". Once again, the retroactive application of excuses for behaviour seems to be done to protect the woman from feeling 
regret or shame for her actions because she knew she was putting her health at risk.

\section{Taking responsibility for condoms}

Most of the women thought both partners were responsible for having condoms. When it came to suggesting they use them, the women seemed to think the men should initiate "because they're the one that actually uses it". In some situations, despite having condoms they still waited for their partner to bring up using a condom. In spite of fearing the slut label, many of the women carried condoms, because they didn't think they could always trust men to remember them. Even though they thought that the man should have condoms, the women still came prepared with their own, but when it came time to use them they faltered saying "It's not that I didn't want to, I just didn't, I don't know why". Once again, there appears to be a disconnect between the intended behaviour and the reality that plays out. It may be that women expect men to take more of a lead role in using condoms, especially if they are on hormonal birth control. The idea of who is responsible for carrying condoms is again muddied by the fear of being labelled as sluts. Although as one participant said, "If you both have the intention to have sex, then you both have the responsibility to have condoms".

\section{Conversations with partners}

None of the women interviewed had ever had a direct conversation with a casual sex partner about STIs. In fact many of the women said they had not had a 'free and frank' discussion with serious boyfriends about their sexual history. In some cases this is because they felt their boyfriends could or would get jealous, which feeds into the perception of women being chaste. Interestingly, one participant pointed out that people can get STIs from serious partners. In her example a friend caught it from her boyfriend, who knew he was positive and never disclosed. This was backed up by a second participant who had a similar story. It seems from these examples that people are not very good about talking to each other about their sexual history. If that is the case, then women are putting themselves further at risk by not using condoms. 
One participant commented that she would ask about STI checks if she knew and trusted the person which seems like a slightly backward process. Women would be willing to have unprotected sex with men before they trusted them enough to have a discussion about their sexual health status. This may again be linked to a women's sexual agency and their reason for sleeping with a man in the first place. If she is looking for a relationship, she may be concerned with scaring him off with a conversation about sexual health early in the piece. These kinds of conversations tend to expose women to judgment. As one participant summed up "women are more classed as the girl you can take home to your parents, or the girl you can $f^{\star *} k$ in the alley". For some women, a longer sexual history may put them at risk of being judged as not 'girlfriend material', to counter this they do not offer the information until they are already in a relationships and it is too late to matter.

\section{The role of men}

"Where else are you going to be learning about it from? An American Pie movie, where all the girls take off their tops and have sex with them? Which is not reality, but perhaps that's how guys think".

The women interviewed all had different views on the roles that men play when it came not only to condoms and casual sex but also to relationships. The majority of women seemed confused about the differing social expectations of men and women and the way these expectations play out in casual sex. The women wanted men to take a greater responsibility for having condoms but they felt that society generally didn't expect men to. While they seemed to agree that men were universally scared of getting a girl pregnant they stated that they wouldn't rely on a man to have condoms on him. Some of the women thought that men didn't care about what they might pass onto their partners, "they don't care about giving it to the girl". They interpreted this lack of caring as a lack of respect towards women.

It is difficult to tell from the interviews whether the women were basing their perception of men on stereotypes or on their own experiences. In one case, a 
woman told the story of a friend who had unprotected sex with a man after he "told her they'd take this pill that doesn't give them diseases". In this case, she laid more blame on the woman for believing the lie, rather than the man for telling it highlighting the within-group pressure that women face regarding their sexuality. Interestingly, when probed a number of the women said they had positive experiences with men who were insistent they use condoms, "in a way you could tell that he really cared about himself, and about the person he was sleeping with". They women felt that men who insisted on condoms were more caring and respectful towards them but still felt this gesture fell outside of the norm.

\section{Education}

"If you're not sexually active, and you've got no intention of being, then nobody needs to tell you, but if you are sexually active, and you haven't been told, that's a problem"

\section{Recalling their own sexuality education}

All the participants had varying memories of their school based sexuality education. Most often however, they had one strong memory, most often associated with STIs or contraception, "Putting a condom on a fake penis, that's all I remember". Almost all of the women recalled attending health classes about puberty and menstruation at the age of eleven or twelve. Education about sex occurred at around 13 or 14 years old although "they were [already] talking about having sex, I kind of didn't even click what half the stuff was on about". Most of the women interviewed commented they were not having sex at the time their school based sexuality education happened and most of the information went over their heads. However, they acknowledged there would have been people in the class who were sexually active and 'if you do it too young, it's just weird. But if you leave it too late, it's just too late".

For the few women who were sexually active at age 13 and 14, there was the consensus that the information "wasn't really life, it wasn't what you needed to know". There were very few classes, with these focusing on contraception and 
disease, and not about having sex and relationship dynamics, which the women commented they would have wanted more information on. It seems that while they talked about sex in class, many of the women may not have been entirely sure of what sex actually was and how it might be enjoyable. Their early recollections mostly related to STIs and how bad it was if you caught one. Interestingly, almost all of the women recalled discussions that the only way to protect from STIs was to use condoms. Given that most of the women interviewed had gone on to have casual sex without condoms at least once, the message clearly did not affect their behaviour, "I suppose there is a link missing there". This may again have been related to the timing of the messages. Most of the women were not sexually active while they were learning about condoms so they felt there was no relevance to their lives and the information about how to do it did not 'stick'. This is despite being able to recall being taught how to use a condom. The participants felt that the information was being delivered in a way that was not relevant to them or their lives and without that context they simply did not pay attention. They noted that everyone matures at different stages and many of the women wish they had been told "even though you think you're not going to have sex, this is still relevant".

\section{Ideas for improving sexuality education}

When directly asked what kinds of things the women thought should be taught in school based sexuality education classes most responded that they wanted "a bit more in-depth, and a bit more, sort of, honest". The women felt their experience of just learning about contraception and STIs was not overly helpful because it did not reflect their lives at the time. The women also felt that they wanted to hear that "it's normal for people to feel like they want to have sex". The message that sex is normal and enjoyable would have been a powerful one for the women interviewed. They felt relationships and the role sex plays could have been a launching off point for discussing contraception, STIs and sexual safety. In many ways, this would be a more natural progression of a sexual health discussion. For young people who do not have any relationship experience, let alone sexual experience, discussing STIs and contraception is essentially putting the cart before the horse. This highlights 
the importance of meeting young people where they are at with sexual health education to make sure that they retain the information. It would seem that the broad brush approach is not translating into healthy sexual behaviour and young people are not equipped with the information they need to cope with relationships and sex.

When the women were making suggestions for improving the curriculum their ideas centred around contextualizing the information so it related to young people, such as women who had been teenage mothers coming to speak to the class. They felt that hearing someone's real life experiences would give meaning to the message that pregnancy can happen to anyone. Listening to the story from someone they could relate to was also a powerful idea as it seemed less like learning in the classroom and more real to them especially, "hearing stories of girls who really screwed up, and guys who really screwed up".

\section{Popular media as a learning tool}

A number of the women suggested that popular media was a way of helping broker the discussion in classrooms. For instance, one participant suggested "they gave, like, a character on Shortland Street, Chlamydia". She elaborated "that's probably going to hit home a lot more than, like, a 50-year-old teacher showing you a picture". There appears to be two appealing angles to this kind of approach. Firstly, Shortland Street and other similar daily soap opera television shows are aimed at a younger generation. In 2011, nearly a quarter of all 18-39 year olds in New Zealand watched Shortland Street and it was the most watched drama on television (TVNZ, 2012). The language and situations are aimed at a younger audience giving it credibility. Secondly, using a popular media channel like a daily soap opera gives both parents and teachers a place to start discussions about sexual health. Even watching a series of clips from the show about a character with an STI, how they got it, how they treated it and what happened could be a powerful learning tool for teachers. 
A second television programme suggested by a participant as a potential learning tool is the American MTV channel show '16 and Pregnant'. This programme is aimed at documenting the lives of young American women who are pregnant as teenagers with each episode focusing on one woman and ultimately showing how hard being a young parent is. One participant noted "they always show afterwards how shit their lives are, that's quite sobering". One of the later episodes from '16 and pregnant' deals with young women who chose to have abortions (MTV, 2010). The women in the special episode also discussed their lack of knowledge about contraception. Programmes like this which are shot documentary style, show real people going through real life events and could be used as conversation starters for teachers. Sexual health educators may even consider making their own New Zealand version of a teenage parenting documentary.

Participants agreed that seeing these kinds of things on television would likely make them pay attention, "If you saw something on TV or you talked about, related to you, then you'd think shit, that could be me". However, simply watching clips of television shows is a relatively passive option for teachers. For the messages to really sink in, young people then need to be able to talk about what they have seen and ask questions. Watching videos such as an introduction before talking to a woman who was a teenage mother allows the students to consider what questions they might like to ask their own preconceptions of teenage mothers and have them direct the conversation.

\section{External experts}

All the participants thought the idea of a nurse/doctor or other health professional coming to the school to talk about sexual health and answer any questions they might have about sex would be helpful. One participant suggested that "everyone write down a question, I don't care how stupid it is, just write it down and throw it in the box, and then just go through all of them in front of everyone". The women felt that having a health professional talk to them would give more authority to the message and students might pay more attention. External experts also offer a degree of anonymity to the students as it is "somebody that the students don't have to see in the corridor the next 
day". The women interviewed felt that young people would be more likely to be honest or ask real questions if they felt they were not going to see the person again. These are similar reasons that young women attend the Family Planning clinic rather than going to their GP for contraception. However, the medical facts of sexual health still need to be embedded in a larger sexuality education curriculum.

\section{Grow the messages with the audience}

All of the women interviewed agreed that more time should be spent on sexuality education at schools, and that classes should continue throughout high school. They proposed a step-wise approach to sexuality education that becomes more and more in-depth as the students get older. The women felt that it was important to start the conversation in years nine and ten because some people would be having sex then but that it should continue as they got older because "the older you get, the more you can take in more seriously". Participants felt that by the time students reach year 12 or 13 they would be more likely to be having sex themselves and would most likely have been in a relationship and "as we established, when you're 16,17, and everyone is starting to have sex, then you've forgotten all that stuff that you learned". This idea of continuing the education so they might better understand the topic might mean the women were looking for more guidance on how to make decisions about sex. Rather than just the STI and condom talk, they wanted a more holistic approach to understanding relationships and sex. This is likely also a good place for conversations about safety, understanding the risks and making considered decisions.

The women wanted sexuality education to be more comprehensive. Similar to the way subjects such as English and Math are taught, students need a progressive education that builds on what they learnt the year before. At present, most students receive a one off block of sexuality education in their health or physical education curriculum. This is unlikely to have the desired effect on young peoples' learning and retention of the information. While schools might not be responsible for the entire gamut of sexuality education, 
they felt that something as complex as sex and relationships needed more attention than it currently receives in schools.

\section{It's more than just sex}

For most of the women interviewed, what they remembered of their school based sexuality education focused solely on contraception and STI prevention. The women stated that they would have liked more information on relationships and the role sex plays in a relationship, with a focus on "the emotional things, of [how] you should only do it when you feel ready, and not when you feel the peer pressure and know everyone else is doing it". More than just stating it, the women wanted to have real information and advice on how to deal with peer pressure from partners and friends about sex as well as advice on relationship violence. The women interviewed felt there was an appetite for better understanding of relationships and the feelings associated with sex and sexuality. Western society still promotes a long-term, monogamous relationship as the norm while offering no advice for young people about what that means or how they can achieve it. The women would like sexuality education to include "teaching people more about what is a relationship, how to make a relationship work".

\section{Summary}

The findings of this study are based on interviews with eleven women aged between 18 and 25, the majority of whom had either completed or were enrolled in tertiary study. Around a quarter of the women volunteered they had experienced an unplanned pregnancy or an STI. Unsurprisingly, alcohol was identified as playing a huge role in the social and sexual lives of these young women. Some women seem to plan on having casual sex when they are drinking, but are unlikely to do so when sober. Drinking alcohol also affects their use of condoms.

The women reported a number of social factors that impacted on their likelihood of having unprotected sex. For some the most prominent was the fear of being labelled as a slut. Rather than having the effect of promoting abstinence, the fear of being thought of as a slut meant they felt too ashamed 
to carry condoms in case anyone noticed. It should be noted that there was a smaller group of women who did carry condoms and who were not concerned about the potential of being labelled a slut. This fear of being judged or thought of as a slut went beyond their peer groups to include strangers. Carrying condoms was also viewed as having the potential to make them seem 'easy' to men.

Almost all of the women could recall attending their school based sexuality education classes although they could only remember covering STIs and contraception. They felt that the information that was presented to them didn't seem relevant to their experiences or feel like it was personalised to them. Half of the women reported their relationship with their mother to be key to their sexual health as she would take them to the doctor for contraception and listen to their concerns. While the women reported talking about sex with their friends they seemed hesitant to call them a trusted information source.

The women suggested a range of ways school based sexuality education could be improved. These ideas focussed on the way in which the messages are delivered, and included suggestions that involvement by other young people who have been teenage parents or had an STI would be beneficial in delivering messages more effectively. The women wanted to hear information and stories from someone who looked and sounded like them and they felt would relate better to information delivered in this way. Participants also suggested involvement by medical professionals and use of popular media would be helpful ways to illustrate the issues. Critically, they identified a gap in the content of the education they had received, stating that, many of the unanswered questions they had were related to aspects of relationships that were not taught such as communication and the emotional aspect of sex and relationships. 


\section{Chapter Five: Discussion}

\section{Introduction}

The aim of this research was to address the gap in knowledge on how, if at all, sexuality education in schools impacts young people's behaviour. By drawing on real life examples having casual sex without a condom the participants were able to reflect on factors that contributed to their decision making. The research considered their lived experience and social context. The research also explored their self-assessed knowledge of sexual health, recollection of their own sexuality education and their ideas for improvements to the sexuality education component of the health and physical education curriculum. The findings of this research place the issue of unprotected casual sex in the context of young people's lives. It is by gaining an understanding of the context, that educators can strive to improve the messages they deliver about sexual safety.

This chapter addresses the research question through three major topics that have emerged both from the existing literature and the findings of this research. They are: alcohol, biology and social-cultural factors (including peer pressure, gender construction and religion). Each of these factors can play a role that can be both protective and encouraging of risky behaviour. These factors also interact in ways that influence young people's behaviour. It is in these interactions that many of the protective factors discussed are eliminated or mitigated. The implications of this research are discussed and a series of recommendations made for sexuality education within and beyond the school environment. This chapter concludes with a discussion of the limitations of the study and areas needing further research.

\section{Alcohol, the ultimate aphrodisiac?}

The relationship between alcohol consumption and unprotected sex has been the subject of extensive research both in New Zealand and internationally. A recent meta-analysis of 12 quantitative studies, 8 of which involved university students, found that "the higher the blood alcohol content, the higher the 
intention to engage in unsafe sex" (Rehm, Shield, Joharchi, \& Shuper, 2012, p. 54). The quantitative findings are also closely aligned with previous qualitative studies with young people showing that they are more likely to have causal sex if they are drinking alcohol (Abel \& Brunton, 2006; S. Brown \& Guthrie, 2010). In New Zealand, 18-25 year olds also have the highest rates of STIs (apart from syphilis) of any age group and have the highest numbers of abortions (Craig, 2009; STI Surveillance Team, 2010). The findings of the present research support the notion that way young people use alcohol and high STI and unplanned pregnancy rates are likely correlated.

For young people in New Zealand there is a clear perception that the consumption of alcohol is a normal part of life. This is supported by data from the New Zealand Ministry of Health, showing that young people aged 18-25 have the highest rates of binge drinking or drinking to get drunk in New Zealand (Ministry of Health, 2009). Binge drinking is characterised by consuming more than five standard drinks for men and four standard drinks for women in one session (Marczinski, Combs, \& Fillmore, 2007; Wechsler, Dowdall, Davenport, \& Rimm, 1995). Research also suggests that adolescents who binge drink do not perform as well in executive functioning tasks (Parada et al., 2012). The authors suggest this is likely due to "the greater vulnerability of the frontal lobes to the neurotoxic effects of alcohol" (Parada, et al., 2012, p. 168) as the frontal lobes are home to the pre-frontal cortex. The pre-frontal cortex is the area of the brain responsible for higher order thinking and decision making.

In the present research, alcohol featured predominantly in participants discussion about casual sex and condom use, and also their lives more generally. They unanimously agreed they were more likely to have casual sex if they had been drinking and they were also less likely to use condoms. These comments are closely aligned with the findings in studies in the UK (Coleman \& Cater, 2005; Cousins, et al., 2010) and the United States (Kiene, et al., 2009) which indicate that this is not a problem unique to New Zealand. 
It is generally agreed that successfully addressing the misuse of alcohol by young people is not something that can be left to schools alone. As a society, New Zealand needs to take a more collective responsibility for the messages we give young people about alcohol. The participants in this study described binge drinking as a 'culture' in New Zealand which was not only accepted but encouraged. Given that alcohol plays a key role in unprotected sex, any sexual safety messages need to acknowledge and address that role.

\section{Blame it on the brain}

There is a clear link between the maturation of the brain and the propensity to take risks. Research shows the development of the prefrontal cortex is not complete until a person reaches their mid twenties (Society for Neuroscience, 2007) however, the limbic system, the home of emotional control and rewardseeking behaviour (Casey, et al., 2008), is fully developed. Research also shows us that during adolescence, the sensation seeking area of the brain is most active (Society for Neuroscience, 2007). In effect, young people have a fully developed reward system, without a fully developed risk assessment system.

There were a great number of contradictions between knowledge of risk and eventual behaviour that the women could not explain. Despite knowing the risks of having casual sex, and their own likely reactions, the women could not clearly articulate why they still went ahead and "did the bad thing anyway". The most extreme example of this being one of the women interviewed who was about to have sex with a casual partner, saw a wart on his penis and had sex without a condom anyway.

Interestingly, the older participants interviewed were more likely to reminisce about past risky experiences from the mid-late teenage years and they considered they had 'grown out' of that kind of behaviour now. Once they reached their early-mid twenties they considered themselves much less likely to have casual sex without condoms and felt more in control of their sexuality. All the women who categorically stated that they did not have casual sex without condoms were close to or 25 years of age, which is the approximate 
age at which the prefrontal cortex reaches maturity. Given that the prefrontal cortex is responsible for much of the higher order reasoning, including decision making and impulse control, we should consider the possibility that there are biological influences for what appear to be bad decisions, that young people have little conscious control over (Casey, et al., 2008; Society for Neuroscience, 2007).

Young people are entering puberty while their brains are still under development. The developmental changes associated with puberty affect their decision making. The function of puberty is to create the hormones that give humans sexual desire - as a signal that their bodies are physically ready to reproduce (Stang \& Story, 2006). The women interviewed in this study expressed that prior acknowledgement or understanding of this physical desire for sex would have been a helpful to hear as they struggled to understand changes to their bodies. While parents and teachers may not consider adolescence mature enough to fully understand sex, their reproductive systems and hormonal desires are saying something different.

Finally, cognitive research clearly shows that adolescents do not process risk and reward the same way as adults (Harris, 1996; Rivers, et al., 2008). A number of the women in this study commented that STIs can be treated with an antibiotic pill so they had little concern about contracting one. This attitude reflects a concept known as 'optimism bias' or a persons natural inclination to underestimate risk and be overly optimistic of their own health (Weinstein, 1980). In an American study involving minority 'at risk' adolescents, the researchers linked the optimism bias to sexual risk taking (Chapin, 2001). The authors found the participants thought they "are not personally susceptible to pregnancy or health risks" (Chapin, 2001 , p. 56). This also explains the "it won't happen to me' feeling many of the women had and their feeling that unplanned pregnancy and STIs were the kind of thing that happen to "other people". 


\section{Making girls into ladies - socio-cultural influences}

Female sexuality has long been the subject of public scrutiny. The findings of this study closely align with other research which illustrates that young women today still feel social pressure to act in certain ways, particularly when around men (Abel \& Brunton, 2006; Tolman, 2003). Women's sexuality and the expectation to behave in certain ways are regulated by peer groups through the use of the 'slut' label. There is no single or clear definition of what a 'slut' is. The women interviewed made similar statements to women in another New Zealand study by Abel \& Brunton (2006) in that they did not want to carry condoms as it made them seem like they 'wanted it'. These women would then be more likely to go on and have unprotected sex because they did not have any condoms. To be seen as 'wanting it' was not something the women thought was socially acceptable and formed the basis of the gender double standard, as men were allowed to express sexual desire.

The women interviewed who reported a strong sense of sexual agency did not allow the slut label to bother them. These were the women who are most likely to use condoms when having casual sex. They have created a safe space for themselves to have casual sex for pleasure and utilise the freedom created by the wide availability of a range of contraceptive methods.

The other major socio-cultural influence for young women is their peers. Research shows however, that what people think of as peer pressure may be in fact a number of different sources of pressure (Maxwell \& Chase, 2008). The findings show that women's perceptions of what other people were doing, or what was normal, pushed them to seek out sexual experiences. However, when they considered their experiences in retrospect, they did not really think everyone was having sex. The fear of being on the outside of an experience or not being cool meant the women put a great deal of pressure on themselves to have sex.

Communicating with parents about sex has been shown to lead to more communication with partners about condoms (Maguen \& Armistead, 2006; 
Ogle, et al., 2008; Whitaker, et al., 1999). Around half of the women interviewed for this study stated they had open and honest conversations with their mothers about sex. Those women felt as though they were able to get good information they could trust and they also felt sorry for friends who did not have that closeness with their mothers. Likewise, research has shown that people in relationships are more likely to use condoms due to intimacy and open communication (Coleman \& Cater, 2005; Raine, et al., 2010). In a society that promotes 'coupling off', young people are more likely to be drawn to relationships as they reflect the accepted norm. However, many of the women interviewed said they had used casual sex as a way to meet men and start relationships. They felt this stemmed from New Zealand not really having a 'dating' culture. The women were unsure of how to meet potential boyfriends other than at parties or going out to bars. They felt dating would be meeting someone in an environment away from these places, so they could get to know each other and they would feel like the men were interested in more than sex. However, most of the women used alcohol to give themselves the courage to talk to men. So while the idea of relationships as a protective factor is interesting, the chance of a woman already having engaged in unprotected sex before there is a commitment to a relationship seems fairly high.

Socio-cultural factors are very difficult to disentangle and can be specific to a religion, geographical area or even an individual family. One of the key messages from this research is that if young women feel a strong sense of control over their sexuality and have high self-esteem they are more likely to use condoms. Women feel in control of their sexuality when they understand that it's acceptable to have sex for pleasure and don't buy into the idea of shaming a girl by calling her a slut. School based sexuality education should be empowering young women to understand that having sex for pleasure is a normal and natural thing for them to do, with the main message being that they do it safely by using condoms. 


\section{Interactions}

Socio-cultural influences interact with each other in complex ways. As an example, one woman interviewed abstained from alcohol but still regularly had casual sex without condoms. This highlights the fact that while alcohol may be a factor/variable in many cases of unprotected sex, on its own, it does not explain why some young people engage in risky behaviour. Eliminating alcohol, or in this case, educating about alcohol alone would not change this young women's risky behaviour. Consideration should then be given to what other factors may have influenced her, and other peoples, risky behaviours.

Research shows that three major factors: alcohol, socio-cultural and biological, can all individually lead to increased risky behaviours, but that they also interact in a variety of ways (Cooper, 2006; Rehm, et al., 2012; Tolman, 2002). Through exploring these interactions a more complex picture of risky behaviour emerges (illustrated in figure 1). This added complexity is likely to have an effect on the way sexuality education is considered and taught.

Figure 1: The interactions between the three key factors

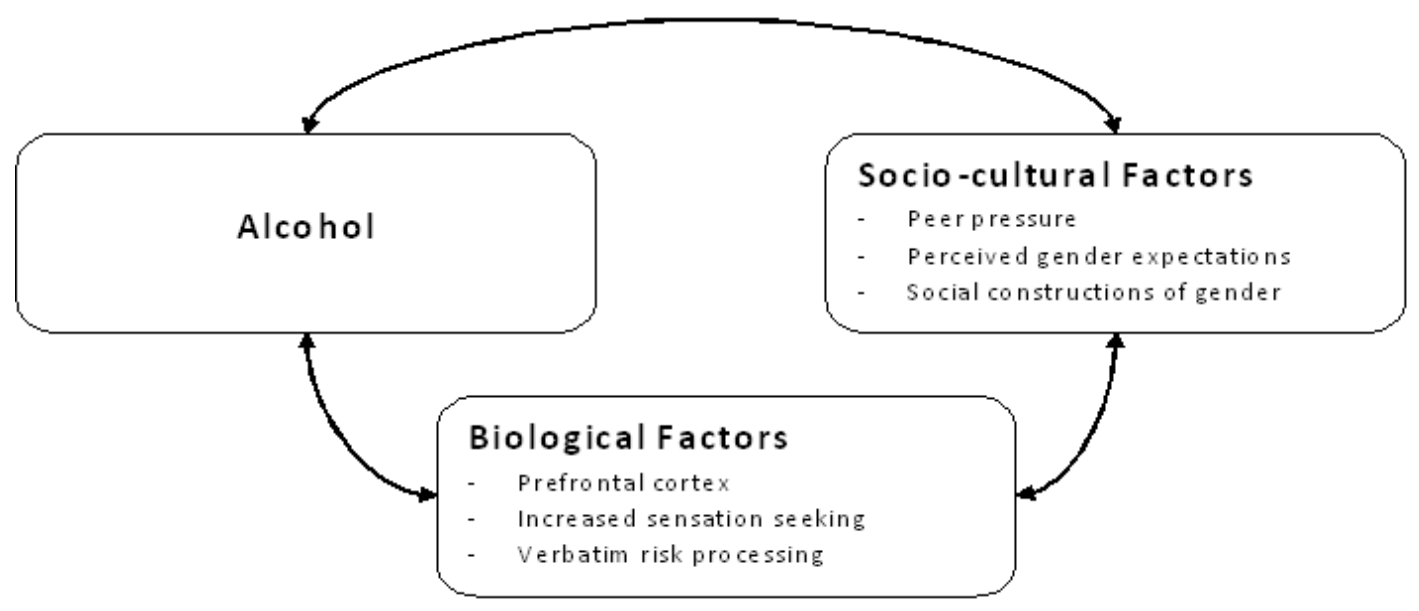

The women in this study almost universally identified alcohol as one factor that could lead to having unprotected casual sex. However, what they are identifying is likely not a direct influence but rather a situational association (Scott-Sheldon, Carey, \& Carey, 2010). This means that when they are most likely to be around alcohol, they are most likely to have casual sex but that 
association they have created is not a true cause and effect relationship. What these associations do not take into account are other factors at the event level (event being when they actually have casual sex) which may also be impacting on a person's choice to have unprotected sex. A 2006 review of studies linking alcohol and casual sex found that the relationship between alcohol and risky sex may not be clear cut (Cooper, 2006). The author found that there may be multiple reasons for the behaviour such as "a person might both drink and have risky sex to satisfy sensation-seeking needs, because of poor impulse control or coping skills, or in an effort to cope with negative emotions" (Cooper, 2006, p. 19). The present study supports the idea that alcohol is a part of the equation but not the whole. The women interviewed reported that they drank alcohol in order to initiate sex. It was always their intention to have sex, and alcohol made the social process of finding a partner easier as it dampened feelings of nervousness and anxiety. However, they may also be passively learning that in order to have sex for pleasure, you need to be drunk. As Cooper (2002) points out, "people believe that alcohol causally promotes risky sexual behaviours. These beliefs, in turn, have been shown to promote drinking in sexual or potentially sexual situations" (p. 112).

The idea of alcohol being a situational association rather than event based is further supported by alcohol being used as an excuse for having, or to have, casual sex. Using alcohol as an excuse for having sex with someone you might not otherwise is well documented in the literature (Coleman \& Cater, 2005). However Cooper (2002) also posits that people actually drink the alcohol first so they will have a socially accepted excuse for their behaviour. Almost all of the women in the present study said they had used alcohol as an excuse for having casual sex with someone they would not otherwise have had sex with.

The importance of alcohol and risky sex at the event level is demonstrated further in an American longitudinal daily diary study of 387 young women aged 14-17 years (Hensel, Stupiansky, Orr, \& Fortenberry, 2011). They found that at the event level alcohol did not have an effect on the non-use of condoms. The authors conclude that "both condom use and non use were 
identified as consistent behavioural patterns, regardless of the effect of marijuana and alcohol use" (Hensel, et al., 2011, p. 239). This research also found some women always had sex with condoms even when they had been drinking while others would not use condoms while sober. This is in line with research by Weinhardt \& Carey (2000) which stated, "people who use condoms when they are sober also tend to use them when drinking; people who fail to use condoms when drinking probably also fail to use them when sober" (p. 125). Further to this, Scott-Sheldon et al (2009), found for women at the event level, the association between condom use and alcohol was also dependant on partner type. The research showed "when a woman and her nonprimary partner were drinking concurrent with sex, they were less likely to use condoms during sex" (Scott-Sheldon, et al., 2009 , p. 768). If condom use is about behavioural constancy, rather than simply the influence of alcohol alone, and women are more likely to not use condoms with casual partners, educators need to rethink some of the messaging to young people about sexual safety.

Peer pressure is another component of casual sex that can be very complex. Maxwell \& Chase (2008) points out that we should be careful when applying the term peer pressure to a situation as it is in itself very contextual, "the context in which a young person finds herself/himself and the pressures within such locations interact with pressure emanating from other sources (such as gendered norms within youth sexuality)" (Maxwell \& Chase, 2008, p. 312). For some young women interviewed in this study, there was a feeling that sex was something they were expected to engage in when they were at parties or out in town drinking. They assumed that the pressure to have sex came from their peer group, although it may have come from other external sources and even from within them.

From a biological perspective, adolescents are physically mature. By their early teens, most women have begun menstruation which allows them to bear children (Stang \& Story, 2006). It is our social and cultural influences that dictate that they should not have sex until they are married or have children until they have finished school. Society should not underestimate the power of 
adolescents' underlying physical drive to reproduce that is coupled with an increased sensation seeking drive (Society for Neuroscience, 2007). Without the benefit of a fully developed prefrontal cortex, young people may simply not have the capacity to comprehend the longer term consequences of engaging in risky sexual behaviour.

It is clear that alcohol, biology or socio-cultural factors alone do not explain risky sexual behaviour. These factors can act in many complex ways that are also dependent on social and personal variables. A 2010 study using event level data from 1946 young adults showed "that risky sexual behaviors cannot be understood in a static, typical, or decontextualized way but rather must be viewed as a complex product of the person, the situation, and the relationship context" (Cooper, 2010, p. 319).

\section{Implications}

High rates of STIs and unplanned pregnancies among young people in New Zealand are important public health issues. The responsibility for educating young people on these issues generally falls to schools. Thanks to the wide availability of contraception, pregnancy is largely preventable and most STIs are easily treated if they are diagnosed early. Reducing the rates of STIs and unwanted pregnancy would have significant personal and public health benefits. If school based sexuality curriculums are to be successful in preparing young people they must take into account the context of their lives and the way they make decisions. This would ideally include an acknowledgement that teenagers are biologically mature and have sexual urges.

Teenage sex and sexuality has been considered a relatively taboo subject in New Zealand historically. In 1998 a comparison of attitudes towards sex between 24 countries found that $71 \%$ of New Zealanders thought teenage sex (defined as under 16 years) was "always wrong" with a further $18 \%$ finding it "almost always wrong" (Widmer, Treas, \& Newcomb, 1998). This is high when compared with countries like Austria (36\% always wrong, 38\% almost always), The Netherlands (45\% always, $24 \%$ almost always) and Sweden 
(32\% always, 28\% almost always) (Widmer, et al., 1998). When the New Zealand Ministry of Health first announced the HPV vaccine would be administered in schools starting in 2009 to girls at age 12, there was concern from parents that it may promote risky sexual behaviour as HPV is an STI. Research in New Zealand regarding the attitudes of parents towards girls having the HPV vaccine showed only around $67 \%$ of parents wanted their daughters to have it at all (Rose, Lawton, Lanumata, Hibma, \& Baker, 2010). Those who didn't want their daughters to have the vaccine "were more likely to be immigrants (over $50 \%$ have English as a second language), and have a religious affiliation" (Rose, et al., 2010, p. 197). The authors concluded that "the rationale for vaccination at age 12 needs to be made clear" to parents as $50 \%$ of respondents thought this was too young (Rose, et al., 2010, p. 198).

Both parents and young people need to feel empowered to openly discuss issues such as contraception and STIs and also the more complex emotional issues such as peer pressure, gender norms and relationships. The provision of school based sexuality education alone is unlikely to be sufficient in changing behaviours. Young people are exposed to an array of messages about gender norms, sex and sexuality from external sources such as the media and their peers. There needs to be a 'joining up' of information that young people receive from schools, parents, medical professionals and the wider community. This should include messages about other situational factors such as the safe and appropriate use of alcohol.

Sexuality education in New Zealand needs to change as it is not meeting the needs of most students (Education Review Office, 2007a). What can be learnt from the success in Uganda and the theoretical models of change is that if we want people to change their behaviour, the links between their risky sexual behaviour and outcomes such as pregnancy and STIs need to be clear. This information also needs to be personalised and relevant to their context. Allen (2011), argues that New Zealand focuses on disease and pregnancy prevention in schools because it fits with the idea that teenage sexuality is "dangerous and problematic" (p. 141). Schools should instead be challenging the "cultural ideal that young people should be non-sexual" (p. 141). Allen 
goes on to argue that sexuality education should be "premised on young people's interests and concerns, as defined by them" (Allen, 2011, p. 154). Students who were surveyed for the research reported the topic they wanted to know was how to make sex more pleasurable, abortion, teenage parenthood, emotions in relationships and breaking up as opposed to "reproduction, periods and puberty" (Allen, 2011, p. 60).

The ERO report found that the characteristics of schools which have contributed to effective sexuality education programmes had more to do with the atmosphere and culture, rather that the content of the individual lessons (Education Review Office, 2007a). These types of characteristics should form the basis of a nationwide approach to sexuality education that, like Uganda, has 'buy in' from government and parents. Lessons should continue to be developed by individual schools to be sure they reflect the needs of their students. Despite the women in this study being past high school age, their information needs were closely aligned to other New Zealand based research (Allen, 2005, 2011). In light of these implications a range of recommendations can be made regarding topics that would ideally be considered for including in future sexuality education programmes.

\section{Recommendations}

\section{Desire and Pleasure - sex isn't all bad}

The notion of desire and pleasure is something that is often omitted from discussions of adolescent sexuality. One of the reasons people have sex is because it is a pleasurable activity both physically and emotionally. Young people are taught about the biological changes occurring during puberty in their early teens however, they also need to know that along with biological changes comes the physical desire to have sex. Aspects of desire are also going to drive behaviour, so young women need to be prepared to act safely to help them better navigate those situations.

It seems natural that school based sexuality education focuses on contraception and STI prevention however with the bad; they should also 
teach the good. Sex is a fundamental part of adult relationships and when practiced safely, should be an enjoyable and pleasurable experience.

\section{It will happen to you - the real risks}

Personalising the message for young people is an important lesson for educators. A clear suggestion from the women interviewed in this study was to bring people into classrooms to share their real life experiences, for example a teenage mother, people who have had STIs, or people with experiences of dating violence. They would like to hear first hand how people got themselves into these situations, and what impact it had on their lives. Participants felt it was important that they receive information from others perceived as similar to themselves, and stressed the importance of putting a human face to the consequences of risky sex. Creating a 'real face' to the story would help to work against young people's innate optimism bias by forcing them to see the story of a woman with an unwanted pregnancy not as a stranger, but a real person who could just as well be them.

\section{Girls just wanna have fun - empowering women to take control of their sexual selves}

Young women need to feel empowered to take control of their sexuality. The wide availability and range of contraceptive methods, many at no or low cost means young women shouldn't be putting themselves at risk of unplanned pregnancy or STIs in order to have sex. They should feel empowered to have casual sex for pleasure if they choose, rather than feeling they have to be in a relationship.

From a schooling perspective this may mean use of a number of different approaches to building a young woman's self esteem and challenging social norms. Schools should consider ways they can challenge underlying assumptions of how girls should act in sexual situations and the notion of what a slut is. Girls also need to understand how to negotiate their sexual safety in different situations, which includes feeling confident to say no to sex when condoms aren't available. 


\section{The New Zealand drinking culture}

While society might be quick to blame alcohol for risky sex the research indicates that the picture is more complex. Directly responsible for unprotected casual sex or not, alcohol has a huge role in the social lives of young people. New Zealand allows and even encourages binge drinking as an activity in itself. Addressing the use and misuse of alcohol by young people and its role in risky behaviours, including causal sex, is an important topic for sexuality education.

Ongoing messages about alcohol and safety are already present in schools. The use of alcohol is discussed in the health curriculum and specialist programmes such as Students Against Drunk Driving (SADD) also exist. Messaging about sex and drinking needs to be focused on making sure young people are prepared and safe when they have casual sex while drinking alcohol.

\section{Helping parents to help their kids}

The 2001 Education Standards Act requires schools to consult with parents and the community about the sexuality component of the curriculum every two years. This consultation could be used as an opportunity to offer advice and support to parents and to talk through the various aspects of sexuality education. Many parents may feel uncomfortable talking to their children about sex and sexuality. These kinds of open forums could give parents the information and confidence to start a conversation with their children, building on their classroom lessons. To help manage an information event like this, schools should consider bringing in outside medical and health experts to answer questions and talk through issues with parents.

\section{Study Limitations}

There are a number of limitations to this research which may impact on the conclusions drawn. Firstly, the women who participated were self-selected through public advertisements so were open to discussing their sexual histories. While that frankness was important for this research, it could have skewed the answers to represent the views of women who were comfortable 
in their sexuality. It should be noted that when discussing sensitive topics such as sex and sexuality participants may have felt pressure to say what they think is the 'socially acceptable' answer. While the interviewer made it clear at the beginning there were no right or wrong answers, or any judgement on their behaviour, this underlying social pressure may have affected some women.

The women were also recalling events from their past. For some women the last time they had casual sex was a number of years ago. It needs to be acknowledged they may not remember the event/s clearly as those for whom the experience was more recent.

The small number of participants required for completion of a qualitative research project meant it was not a representative sample of 18-25 year old women in New Zealand. Demographic data indicated that most participants had either completed, or were currently enrolled in tertiary education, so as a group they had a higher level of education than the general population in this age-group. They were also predominately New Zealand European.

\section{Future Research}

As with the majority of previous studies, the current study involved women. However, men too are subjected to social constructions of their gender and likely face a different set of sexual expectations. Further research that involves males is needed to give a better understanding of their experiences of sex and sexuality and the factors that come into play for males when engaging in casual sex without the use of condoms. The issues raised here will affect young men in different ways as they are also developing into their sexual selves while under intense social pressure. Future research should also look to compare the way women describe male sexuality with how men describe their own beliefs.

One of the key themes to emerge from this research is that educators are thought to require a better understanding of young people's lives in order to pitch sexuality education at an appropriate level. However what might be 
appropriate for some groups may not be appropriate in New Zealand's increasingly diverse social and ethnic communities. As the 2007 ERO report found, New Zealand secondary schools are particularly weak in teaching to diverse groups of student (Education Review Office, 2007a). While this will have highlighted some overlapping contextual issues that are relevant for all young New Zealanders, future research should focus more specifically on Maori, Pacific and the growing Asian populations. Consideration should also be given to the diversifying religious sectors in New Zealand including the growing Muslim population and how their needs might be different.

The women who participated in this study were not directly asked to disclose their sexual orientation as the focus was on condom use during casual sex between men and women. People who identify as Lesbian, Bisexual, Gay and Transgender (LGBT) are still able to contract STIs and have an unplanned pregnancy. Allen (2011), comments on schools being 'heteronormative' and that sexuality education currently "presumes desire, sexual practice and identity are universally heterosexual" (p. 3). The coming out process, the issues of sexual identity and the social discrimination these people still face adds further complexity to their sexual lives and it would be useful to undertake further research involving these groups to gain a greater understanding of those unique pressures.

\section{Conclusion}

It is also important to note that not everybody will engage in unprotected casual sex. For those who do the relationship between condom use and casual sex is complex. While it may be a common view that alcohol alone increases the likelihood of having casual sex without condoms, in reality it is more likely that alcohol is one of a number of factors within a broad and more complex set of interacting factors. Alcohol was used as a tool by some of these young women to aide social and sexual situations rather than the root cause of casual sex.

From a biological perspective, having casual sex is a natural response as young women are physically mature so they have an active sex drive. Conflict 
and tension arises when social expectations of sexuality are placed on women that suggest sex is something that should be reserved for relationships and reproduction, not for pleasure. By internalised these conflicting messages, young women are essentially shamed into thinking that having sex for pleasure is a bad thing. The regulation of these social norms and expectations occurs through use of the 'slut' label by peers. While many women fear being thought of as a slut, rather than going without sex, they may instead engage in casual sex but be unprepared by not carrying condoms. While some may use hormonal contraception this offers them no protection from STIs.

Sexuality educators need to convey a different message than they currently do about sex and sexuality. Women participating in this study were clear about what they wanted to know, i.e., that it is ok to want to have sex and that they can choose to have casual sex if they want. They want to hear that they are allowed to take control of their sexual experiences but they need to know how to do that safely. These messages need to be personalised in a way that young people understand unprotected casual sex is risky and STIs and unplanned pregnancy can happen to them. The role of parents in providing complementary sexuality education from home is an important protective aspect. While schools might take the lead, parents need to be educated and enabled to have conversations with young people about sex. Further to these issues is the role of alcohol in New Zealand's society. While alcohol may not actually be a direct cause of unprotected casual sex, it is used as an excuse for engaging in risky behaviours. New Zealand as a whole needs to consider the importance young women place on alcohol as a key part of their social life. The work required to affect real change in this area is greater than school based sexuality education programmes. 


\section{Chapter Six: References}

Abel, G., \& Brunton, C. (2005). Young people's use of condoms and their perceived vulnerability to sexually transmitted infections. Australian and New Zealand Journal of Public Health, 29(3), 254-260.

Abel, G., \& Brunton, C. (2006). When you come to it you feel like a dork asking a guy to put a condom on: is sex education addressing young people's understandings of risk? Sex Education: Sexuality, Society and Learning, 6(2), 105 - 119.

Abortion Services in New Zealand. (2006). Legal Information, from http://www.abortion.gen.nz/legal/index.html

Abortion Supervisory Committee. (2011). Supplementary Report of the Abortion Supervisory Committee. Wellington.

Adolescent Health Research Group. (2008). Youth'07: The Health and Wellbeing of Secondary School Students in New Zealand. Initial Findings. Auckland: The University of Auckland.

Advocates for Youth. (2011). Adolescent Sexual Health in Europe and the US, 19 April, 2012, from

http://www.advocatesforyouth.org/publications/publications-a-z/419adolescent-sexual-health-in-europe-and-the-us

Allen, L. (2005). Say everything: exploring young people's suggestions for improving sexuality education. Sex Education: Sexuality, Society and Learning, 5(4), 389 - 404.

Allen, L. (2011). Young People and Sexuality Education: Rethinking Key Debates. New York: Palgrave MacMillan.

Anuta, J. (2006). What makes a song catchy? Retrieved from http://www.physorg.com/news69003006.html

Ash, J. (2010). Severely drunk women shock police The Dominion Post. Associated Press. (2011). 'SlutWalk' marches sparked by Toronto officer's remarks, BBC News. Retrieved from http://www.bbc.co.uk/news/worldus-canada-13320785

Auckland Sexual Health Service. Chlamydia and Gonorrhoea Pages

Retrieved 7 September 2011, from www.everybody.co.nz 
Bandura, A. (1998). Health promotion from the perspective of social cognitive theory. Psychology and Health, 13, 623-649.

Baryarama, F., Bunnell, R. E., Ransom, R. L., Ekwaru, J. P., Kalule, J., Tumuhairwe, E. P., et al. (2004). Using HIV Voluntary Counseling and Testing Data for Monitoring the Uganda HIV Epidemic, 1992-2000. J Acquir Immune Defic Syndr, 37(1).

Bay-Cheng, L. Y. (2003). The Trouble of Teen Sex: the construction of adolescent sexuality through school-based sexuality education. Sex Education: Sexuality, Society and Learning, 3(1), 61 - 74.

BBC News. (2005). Factfile: Roman Catholics around the world from http://news.bbc.co.uk/2/hi/4243727.stm

Bearman, P. S., \& Brackner, H. (2001). Promising the Future: Virginity Pledges and First Intercourse. The American Journal of Sociology, 106(4), 859-912.

Begoray, D. L., Wharf-Higgins, J., \& MacDonald, M. (2009). High school health curriculum and health literacy: Canadian student voices. Global Health Promotion, 16(4), 35-42.

Bellis, M., Hughes, K., Calafat, A., Juan, M., Ramon, A., Rodriguez, J., et al. (2008). Sexual uses of alcohol and drugs and the associated health risks: A cross sectional study of young people in nine European cities. Bmc Public Health, 8(1), 155.

Black, C., McGough, P., Bigrigg, A., \& Thow, C. (2005). What do clients of a young people's sexual health service recall about their sex education programme at school? European Journal of Contraception and Reproductive Health Care, 10(4), 235-243.

Blas, M. M., Canchihuaman, F. A., Alva, I. E., \& Hawes, S. E. (2007). Pregnancy outcomes in women infected with Chlamydia trachomatis: a population-based cohort study in Washington State. Sexually Transmitted Infections, 83:, 314-318.

Boden, J. M., Fergusson, D. M., \& Horwood, L. J. (2011). Alcohol and STI risk: Evidence from a New Zealand longitudinal birth cohort. Drug and Alcohol Dependence, 113(2-3), 200-206. 
Brady, M. (2003). Preventing Sexually Transmitted Infections and Unintended Pregnancy, and Safeguarding Fertility: Triple Protection Needs of Young Women. Reproductive Health Matters, 11(22), 134-141.

Brom, R. H. (2004). Birth Control, from http://www.catholic.com/tracts/birthcontrol

Brown, J. T., Conte, J., Foxx, J., Henderson, C., Melanchon, B. R., Nash, T., et al. (2008). Blame it (On the Alcohol) [Recorded by Jamie Foxx]. On Intuition [CD]. United States: J Records.

Brown, S., \& Guthrie, K. (2010). Why don't teenagers use contraception? A qualitative interview study. The European Journal of Contraception and Reproductive Health Care, 15, 197-204.

Byno, L. H., Mullis, R. L., \& Mullis, A. K. (2009). Sexual behavior, sexual knowledge, and sexual attitudes of emerging adult women: implications for working with families. Journal of Family Social Work, 12(4), 309322.

Byrne, M. M. (2001). Understanding life experiences through a phenomenological approach to research. AORN, 73(4), 830-832.

Casey, B. J., Jones, R. M., \& Hare, T. A. (2008). The Adolescent Brain. Annals of the New York Academy of Science, 1124, 111-126.

Centre for Disease Control and Prevention. (2012). Gynecologic Cancers: Cervical Cancer Risk Factors, from http://www.cdc.gov/cancer/cervical/basic info/risk factors.htm

Chapin, J. (2001). It Won't Happen to Me: The Role of Optimistic Bias in African American Teens' Risky Sexual Practices. Howard Journal of Communications, 12(1), 49-59.

Clifford, G. M., Smith, J. S., Aguado, T., \& Franceschi, S. (2003). Comparison of HPV type distribution in high-grade cervical lesions and cervical cancer: a meta-analysis. Br J Cancer, 89(1), 101-105.

Coleman, L. M., \& Cater, S. M. (2005). A qualitative study of the relationship between alcohol consumption and risky sex in adolescents. Arch Sex Behav, 34(6), 649-661.

Collins, J. L., \& Champion, J. D. (2009). Male Adolescent Sexual Behavior What They Know and What They Wish They Had Known. Western Journal of Nursing Research, 31(6), 748-771. 
Cooper, M. L. (2002). Alcohol use and risky sexual behavior among college students and youth: evaluating the evidence. Journal of studies on alcohol. Supplement(14), 101-117.

Cooper, M. L. (2006). Does Drinking Promote Risky Sexual Behavior?: A Complex Answer to a Simple Question. Current Directions in Psychological Science, 15(1), 19-23.

Cooper, M. L. (2010). Toward a Person X Situation Model of Sexual RiskTaking Behaviors:Illuminating the Conditional Effects of Traits Across Sexual Situations and Relationship Contexts. Journal of Personality and Social Psychology, 98(2), 319-341.

Cormack, D., \& Harris, R. (2009). Issue in Monitoring Maori Health and Ethnic Disparities: An Update. Wellington: Te Ropu Rangahau Hauora a Eru Pomare.

Cousins, G., Mc Gee, H., \& Layte, R. (2010). Suppression Effects of Partner Type on the Alcohol-Risky Sex Relationship in Young Irish Adults. Journal of Studies on Alcohol and Drugs, 71(3).

Craig, E., Anderson, P., \& Jackson, C. (2009). The Health Status of Children and Young People in the Capital and Coast DHB: University of Auckland.

Crego, A., Rodriguez-Holguín, S., Parada, M., Mota, N., Corral, M., \& Cadaveira, F. (2010). Reduced anterior prefrontal cortex activation in young binge drinkers during a visual working memory task. Drug and Alcohol Dependence, 109(1-3), 45-56.

Crotty, M. (1998). The Foundations of Social Research: Meaning and Perspective in the Research Process. Australia: Allen \& Unwin.

Darroch, J. E., Frost, J. J., \& Singh, S. (2001). Teenage Sexual and Reproductive Behavior in Developed Countries: Can more progress be made? New York: The Guttmacher Institute.

De Genna, N. M., Larkby, C., \& Cornelius, M. D. (2007). Early and adverse experiences with sex and alcohol are associated with adolescent drinking before and during pregnancy. Addictive Behaviors, 32(12), 2799-2810. 
Dewar, S. (2001). Implementing Health and Physical Education in the New Zealand Curriculum: A Report of the Experiences of a National Sample of Schools. The Research Bulletin, 12, 81-97.

DiCenso, A., Guyatt, G., Willan, A., \& Griffith, L. (2002). Interventions to reduce unintended pregnancies among adolescents: systematic review of randomised controlled trials. BMJ, 324(7351).

Dickenson, N., Wilson, M., Herbison, P., \& Paul, C. (2002). Unwanted pregnancies involving young women and men in a New Zealand birth cohort. New Zealand Medical Journal, 115(1151), 155-159.

Donadio, R. (2010). In Rare Cases, Pope Justifies Use of Condoms, The New York Times. Retrieved from http:/www.nytimes.com/2010/11/21/world/europe/21pope.html? $\quad r=1 \& s$ $\mathrm{cp}=1 \& \mathrm{sq}=\mathrm{pope} \% 20$ condoms\&st=cse

Downing-Matibag, T. M., \& Geisinger, B. (2009). Hooking Up and Sexual Risk Taking Among College Students: A Health Belief Model Perspective. Qualitative Health Research, 19(9), 1196-1209.

Education Review Office. (2007a). The Teaching of Sexuality Education in Years 7 to 13. Wellington: Education Review Office.

Education Review Office. (2007b). The Teaching of Sexuality Education in Years 7 to 13: Good Practice. Wellington.

Education Review Office. (2011). Evaluation of Teen Parent Units.

Wellington.

Family Planning Association. (2011a). Family Planning Retrieved 22 July 2011, from http://www.familyplanning.org.nz/education training

Family Planning Association. (2011b). Sexually Transmissible Infections (STIs). In F. P. Association (Ed.).

Ferguson, R. M., Vanwesenbeeck, I., \& Knijn, T. (2008). A matter of facts and more: an exploratory analysis of the content of sexuality education in The Netherlands. Sex Education: Sexuality, Society and Learning, 8(1), $93-106$.

Fielder, R. L., \& Carey, M. P. (2010). Predictors and Consequences of Seuxal "Hookups" Among College Students: A Short-term Prospective Study. Arch Sex Behav, 39, 1105-1119. 
Ford, K., Sohn, W., \& Lepkowski, J. (2001). Characteristics of Adolescents' Sexual Partners and Their Association with Use of Condoms and Other Contraceptive Methods. Family Planning Perspectives, 33(3), 100-132. Gilmartin, S. (2006). Changes in College Women's Attitudes Towards Sexual Intimacy. Journal of Research on Adolescence, 16(3), 429-454.

Giuliano, A. R., Palefsky, J. M., Goldstone, S., Moreira, E. D., Penny, M. E., Aranda, C., et al. (2011). Efficacy of Quadrivalent HPV Vaccine against HPV Infection and Disease in Males. New England Journal of Medicine, 364(5), 401-411.

Glanz, K., \& Bishop, D. B. (2010). The Role of Behavioral Science Theory in Development and Implementation of Public Health Interventions. Annual Review of Public Health, 31(1), 399-418.

Glanz, K., Rimer, B. K., \& Viswanath, K. (2008). Health Behavior and Health Education: Theory, Research, and Practice (Vol. 4): John Wiley and Sons.

Goldstone, S. E., \& Moshier, E. (2010). Detection of Oncogenic Human Papillomavirus Impacts Anal Screening Guidelines in Men Who Have Sex With Men. Diseases of the Colon and Rectum, 53(8).

Grello, C. M., Welsh, D. P., \& Harper, M. S. (2006). No Strings Attached: The nauture of casual sex in college students. Journal of Sex Research, 43(3), 255-267.

Grose-Fifer, J., Hoover, S., Zottoli, T., \& Rodrigues, A. (2011). Expecting the unexpected: An N400 study of risky sentence processing in adolescents. Psychophysiology, 48(9), 1184-1191.

Harris, P. (1996). Sufficient Grounds for Optimism?: The Relationship Between Perceived Controllability and Optimistic Bias. Journal of Social and Clinical Psychology, 15(1), 9-52.

Haywood, D., Kear, D., Kelley, C., \& Scott, H. (2009). Need You Now [Recorded by Lady Antebellum]. On Need You Now [CD]. New York: Capitol Nashville.

Hensel, D. J., Stupiansky, N. W., Orr, D. P., \& Fortenberry, J. D. (2011). Event-Level Marijuana Use, Alcohol Use, and Condom Use Among Adolescent Women. Sexually Transmitted Diseases, 38(3), 239-243. 
Herold, E. S., \& Mewhinney, D. K. (1993). Gender Differences in Casual Sex and AIDS Prevention: A Survey of Dating Bars. The Journal of Sex Research, 30(1), 36-42.

Hillier, L. (1998). "When you carry a condoms all the boys think you want it": Negotiating competing discourses about safe sex. Journal of Adolescence, 21(15-29).

Ingham, R. (2005). "We Didn't Cover that at School": Education "against" Pleasure or Education "for" Pleasure? Sex Education: Sexuality, Society and Learning, 5(4), 375-388.

Janz, N. K., \& Becker, M. H. (1984). The Health Belief Model: A Decade Later. Health Education \& Behavior, 11(1), 1-47.

Kane, R. (2008). Sex and relationship education: bridging the gap between research and practice. Health Education, 108(1), 5-9.

Kiene, S. M., Barta, W. D., Tennen, H., \& Armeli, S. (2009). Alcohol, Helping Young Adults to Have Unprotected Sex with Casual Partners: Findings from a Daily Diary Study of Alcohol Use and Sexual Behavior. Journal of Adolescent Health, 44(1), 73-80.

Kirby, D. (2007). Emerging Answers: Research findings on Programs to Reduce Teen Pregnancy and Sexually Transmitted Disease.

Washington DC: National Campaign to Prevent Teen and Unwanted Pregnancy.

Kirby, D. (2008). Success in Uganda: A Review of Programmatic Approaches to AIDS Prevention and Their Impact 1986-1995.

Kirby, D. (2010). Behavioral Messages To Prevent Pregnancy and STI, What Should They Be? Paper presented at the Family Planning Conference Wellington.

Kirby, D., \& Halperin, D. (2008). Success in Uganda: An Analysis of Behaviour Changes that Led to Declines in the Prevalence in the Early 1990s

Kiwi Families. (2007). Legal age guidelines Retrieved 7 September, 2011, from http://www.kiwifamilies.co.nz/topics/parenting/legal-ageguidelines.html

Koob, G. F. (2003). Alcoholism: Allostasis and Beyond. Alcoholism: Clinical and Experimental Research, 27(2), 232-243. 
Kretzschmar, M., \& Morris, M. (1996). Measures of concurrency in networks and the spread of infectious disease. Mathematical Biosciences, 133(2), 165-195.

Kühberger, A., Schulte-Mecklenbeck, M., \& Perner, J. (1999). The Effects of Framing, Reflection, Probability, and Payoff on Risk Preference in Choice Tasks. Organizational Behavior and Human Decision Processes, 78(3), 204-231.

Kypri, K., \& Langley, J. D. (2003). Perceived social norms and their relation to university student drinking. Journal of Studies on Alcohol, 64(6), 829834.

Kypri, K., Langley, J. D., McGee, R., Saunders, J. B., \& Williams, S. (2002). High Prevalence, Persistant Harzardous Drinking among New Zealand Tertiary Students. Alcohol and Alcoholism, 37(5), 457-464.

Kypri, K., Paschall, M. J., Langley, J., Baxter, J., Cashell-Smith, M., \& Bourdeau, B. (2009). Drinking and Alcohol-Related Harm Among New Zealand University Students: Findings From a National Web-Based Survey. Alcoholism-Clinical and Experimental Research,, 33(2), 307314.

Landry, D. J., Kaeser, L., \& Richards, C. L. (1999). Abstinence promotion and the provision of information about contraception in public school district sexuality education policies. Family Planning Perspectives, 31, 280286.

Laraque, D., McLean, D. E., Brown-Peterside, P., Ashton, D., \& Diamond, B. (1997). Predictors of reported condom use in central Harlem youth as conceptualized by the Health Belief Model. The Journal of adolescent health : official publication of the Society for Adolescent Medicine, 21(5), 318-327.

Laverty, S. M. (2003). Hermeneutic Phenomenology and Phenomenology: A Comparison of Historical and Methodological Considerations International Journal of Qualitative Methods, 2(3).

Lee, J. T., Tsai, J. L., Tsou, T. S., \& Chen, M. C. (2011). Effectiveness of a theory-based postpartum sexual health education program on women's contraceptive use: a randomized controlled trial. Contraception, 84(1), 48-56. 
Lesta, S., Lazarus, J. V., \& Essen, B. (2008). Young Cypriots on Sex Education: Sources and Adequacy of Information Received on Sexuality Issues. Sex Education: Sexuality, Society and Learning, 8(2), 237-246.

Lindau, S. T., Tetteh, A., Kasza, K., Gilliam, M. (2008). What Schools Teach Our Patients About Sex: Content, Quality, and Influences on Sex Education. 256-266.

Lipp, A. (2009). Termination of pregnancy: a review of psychological effects on women. Nursing Times, 105(1), 26-29.

Lopez, L. M., Tolley, E. E., Grimes, D. A., \& Chen-Mok, M. (2011). Theorybased interventions for contraception. Cochrane Database of Systematic Reviews, (3). Retrieved from http://www.mrw.interscience.wiley.com/cochrane/clsysrev/articles/CD0 07249/frame.html doi:10.1002/14651858.CD007249.pub3

Maguen, S., \& Armistead, L. (2006). Abstinence among female adolescents: Do parents matter above and beyond the influence of peers? American Journal of Orthopsychiatry, 76(2), 260-264.

Makenzius, M., Gadin, K. G., Tyden, T., Romild, U., \& Larsson, M. (2009). Male students' behaviour, knowledge, attitudes, and needs in sexual and reproductive health matters. The European Journal of Contraception and Reproductive Health Care, 14(4), 268-276.

Manning, W. D., Longmore, M. A., \& Giodano, P. C. (2005). Adolescents' involvement in non-romantic sexual activity. Social Science Research, 34, 384-407.

Manning, W. D., Longmore, M. A., \& Giodano, P. C. (2006). Hooking Up: The Relationship Contexts of "Nonrelationship" Sex. Journal of Adolescent Research, 459-483.

Marczinski, C. A., Combs, S. W., \& Fillmore, M. T. (2007). Increased sensitivity to the disinhibiting effects of alcohol in binge drinkers. Psychology of Addictive Behaviors, 21(3), 346-354.

Marshall, C. S., \& Reinhartz, J. (1997). Gender Issues in the Classroom. The Clearing House, 70(6).

Matziou, V., Perdikaris, P., Petsios, K., Gymnopoulou, E., Galanis, P., \& Brokalaki, H. (2009). Greek students' knowledge and sources of 
information regarding sex education. International Nursing Review, 56(3), 354-360.

Maxwell, C., \& Chase, E. (2008). Peer pressure: beyond rhetoric to reality. Sex Education: Sexuality, Society and Learning, 8(3), 303 - 314.

Mazengarb, O. C. (1954). The Special Committee on Moral Delinquency in Children and Adolescents. Wellington: R.E Owen.

McConnell-Henry, T., Chapman, Y., \& Francis, K. (2009). Unpacking Heideggerian Phenomenology. Southern Online Journal of Nursing Research, 9(1).

McGee, R., Williams, S., \& Kypri, K. (2010). College students' readiness to reduce binge drinking: Criterion validity of a brief measure. Drug and Alcohol Dependence, 109(1-3), 236-238.

Merriam, S. B. (2009). Qualitative research: A guide to design and implementation. San Francisco: Jossey-Bass.

Ministry of Education. (1999). Health and Physical Education in the New Zealand Curriculum. Wellington: Learning Media Ltd Retrieved from http://nzcurriculum.tki.org.nz/.

Ministry of Education. (2007). The New Zealand Curriculum Wellington:

Learning Media Ltd Retrieved from

http://nzcurriculum.tki.org.nz/Curriculum-documents/The-New-ZealandCurriculum.

Ministry of Health. (2001). Sexual and Reproductive Health Strategy: Phase

One. Wellington: Ministry of Health.

Ministry of Health. (2003). Teachers' Guide to Sexual Health: Sexuality

Education for Year 9 and 10 Students in Secondary Schools.

Wellington.

Ministry of Health. (2008). Chlamydia Management Guidelines. In M. o.

Health (Ed.). Wellington: Ministry of Health.

Ministry of Health. (2009). Alcohol Use in New Zealand: Key results of the 2007/08 New Zealand Alcohol and Drug Use Survey. Wellington: Ministry of Health.

Ministry of Health. (2011). Sexual Health: Healthed Retrieved 22 July, 2011, from https://www.healthed.govt.nz/health-topic/sexual-health 
Morgan, J. (2008). Testing and detection trends of Chlamydia trachomatis and Neisseria gonorrhoeae in Waikato, New Zealand: 1998-2006. New Zealand Medical Journal, 121(1278).

MTV. (2010). No Easy Decision. 16 and Pregnant: MTV.

New Zealand Parliamentarians' Group on Population Development. (2006). Youth Sexual Health: Our Health, Our Issue Wellington.

Ogle, S., Glasier, A., \& Riley, S. C. (2008). Communication between parents and their children about sexual health. Contraception, 77(4), 283-288.

Oscar-Berman, M., \& Marinković, K. (2007). Alcohol: Effects on Neurobehavioral Functions and the Brain. Neuropsychology Review, 17(3), 239-257.

Parada, M., Corral, M., Mota, N., Crego, A., Holguin, S. R., \& Cadaveira, F. (2012). Executive functioning and alcohol binge drinking in university students. Addictive Behaviors, 37(2), 167-172.

Pascal, J. (2010). Phenomenology as a Research Method for Social Work Contexts: Understanding the Lived Experience of Cancer Survival. Currents: New Scholarship in the Human Services, 9(2).

Patton, M. Q. (2002). Qualitative Research \& Evaluation Methods (3 ed.). Thousand Oaks: Sage Publications Inc

Paul, E. L., \& Hayes, K. A. (2002). The casualities of 'casual' sex: A qualitative exploration of the phenomenology of college students' hookups. Journal of Social and Personal Relationships, 19(5), 639-661.

Pedrelli, P., Bitran, S., Shyu, I., Baer, L., Guidi, J., Tucker, D. D., et al. (2011). Compulsive Alcohol Use and Other High-Risk Behaviors among College Students. [Article]. American Journal on Addictions, 20(1), 1420.

Pitts, S. (2003). What do Students Learn when we Teach Music? : An Investigation of the 'Hidden' Curriculum in a University Music Department. Arts and Humanities in Higher Education, 2(3), 281-292.

Prochaska, J. O., \& Velicer, W. F. (1997). The Transtheoretical Model of Health Behavior Change. American Journal of Health Promotion, 12(1), 38-48.

QSR International Ltd. (2009). Nvivo 8. Retrieved from http://www.qsrinternational.com/default.aspx\#tab you 
Raine, T. R., Gard, J. C., Boyer, C. B., Haider, S., Brown, B. A., Antonio Ramirez Hernanadez, F., et al. (2010). Contraceptive decision-making in sexual relationships: young men's experiences, attitudes and values. Culture, Health and Sexuality, 12(4), 373-386.

Rehm, J., Shield, K. D., Joharchi, N., \& Shuper, P. A. (2012). Alcohol consumption and the intention to engage in unprotected sex: systematic review and meta-analysis of experimental studies. Addiction, 107(1), 51-59.

Reyna, V. F., Estranda, S. M., DeMarinis, J. A., Myers, R. M., Stanisz, J. M., \& Mills, B. (2011). Neurobiological and Memory Models of Risky Decision Making in Adolescents Versus Young Adults. Journal of Experimental Psychology: Learning, Memory and Cognition, 37(5), 1125-1142.

Rivers, S. E., Reyna, V. F., \& Mills, B. (2008). Risk taking under the influence: A fuzzy-trace theory of emotion in adolescence. Developmental Review, 28(1), 107-144.

Rose, S. B., Lawton, B. A., Lanumata, T., Hibma, M., \& Baker, M. G. (2010). HPV/cervical cancer vaccination: parental preferences on age, place and information needs. Journal of Primary Health Care, 2(3), 190-198.

Rose, S. B., Smith, M. C., \& Lawton, B. A. (2008). "If everyone does it, it's not a big deal." Young people talk about chlamydia testing. $N Z$ Med $\mathrm{J}$, 121(1271), 33-42.

Rosenstock, I. M., Strecher, V. J., \& Becker, M. H. (1988). Social Learning Theory and the Health Belief Model. Health Education \& Behavior, 15(2), 175-183.

Ryan, S., Franzatta, K., Manlove, J., \& Holcombe, E. (2007). Adolescents' discussions about contraception or STDs with partners before first sex. Perspectives on Sexual and Reproductive Health, 39(3).

Scott-Sheldon, L., Carey, M., \& Carey, K. (2010). Alcohol and Risky Sexual Behavior Among Heavy Drinking College Students. AIDS and Behavior, 14(4), 845-853.

Scott-Sheldon, L., Carey, M., Vanable, P., Senn, T., Coury-Doniger, P., \& Urban, M. (2009). Alcohol Consumption, Drug Use, and Condom Use 
Among STD Clinic Patients. Journal of Studies on Alcohol and Drugs, 70(5), 762-770.

Sinkinson, M., \& Burrows, L. (2011). Reframing health education in New

Zealand/Aotearoa schools. Asia-Pacific Journal of Health, Sport and

Physical Education, 2(3), 53-69.

Skinner, S. R., Smith, J., Fenwick, J., Hendriks, J., Fyfe, S., \& Kendall, G. (2009). Pregnancy and protection: Perceptions, attitudes and experiences of Australian female adolescents. Women and Birth, 22(2), 50-56.

Smith, E. M., Hoffman, H. T., Summergill, K. S., Kirchner, H. L., Turek, L. P., \& Haugen, T. H. (1998). Human Papillomavirus and Risk of Oral Cancer. The Laryngoscope, 108, 1098-1103.

Society for Neuroscience. (2007). The Adolescent Brain. The Brain Briefings, January 2007.

Stang, J., \& Story, M. (2006). Adolescent Growth and Development In J. Stang \& M. Story (Eds.), Guidelines for Adolescent Nutrition Services. Minneapolis, MN: Center for Leadership, Education and Training in Maternal and Child Nutrition, Division of Epidemiology and Community Health, School of Public Health, University of Minnesota.

Statistics New Zealand. (2006). 2006 Census. Wellington: Statistics New

Zealand Retrieved from

http://www.stats.govt.nz/Census/2006CensusHomePage/QuickStats/q uickstats-about-a-subject/culture-and-identity/religious-affiliation.aspx.

Statistics New Zealand. (2011a). Abortion Statistics: Year ended December 2010. Wellington.

Statistics New Zealand. (2011b). Demographic Trends: 2011 Retrieved 18 February, 2012, from http://www.stats.govt.nz/browse for stats/population/estimates and pr ojections/demographic-trends-2011/births.aspx

Statistics New Zealand. (2012). Demographic Trends: 2011. Wellington. STI Surveillance Team. (2010). Sexually Transmitted Infections in New Zealand Annual Surveillance Report 2009. In S. S. Team (Ed.). Wellington: Institute of Environmental Science and Research Limited. 
STI Surveillance Team. (2011). Sexually transmitted infections in New Zealand: Annual Surveillance Report 2010. Wellington.

Suvivuo, P., Tossavainen, K., \& Kontula, O. (2009). Contraceptive use and non-use among teenage girls in a sexually motivated situation. Sex Education: Sexuality, Society and Learning, 9(4), 355 - 369.

Sylva, K., Melhuish, E., Sammons, P., Siraj-Blatchford, I., Taggart, B., Hunt, S., et al. (2008). Final Report from the Primary Phase: Pre-school, School and Family Influences on Children's Development During Key Stage 2 (Age 7-11). London: Retrieved from https://www.education.gov.uk/publications/eOrderingDownload/DCSFRB061.pdf.

The Church of England. (2005). Statements on Science, Medicine, Technology \& Environment, from http://web.archive.org/web/20060810021928/http://www.cofe.anglican. org/info/socialpublic/smte.html

The General Board of Church and Society of the United Methodist Church.

(2008). Responsible Parenthood, from http://www.umcgbcs.org/site/c.frLJK2PKLqF/b.3794227/apps/s/content.asp?ct=420695 $\underline{7}$

The Presbyterian Church of the USA. (2010). IRS Tax-Qualified Healthcare Expenses, from http://web.pensions.org/Publications/pensions/Home/Forms\%20\%26\% 20Publications/Booklets\%20\%26\%20Brochures/IncentiveIRSTaxQualified.pdf

TNS. (2005). Safer Sex Evaluation Summary. Wellington.

Tolman, D. (2002). Delemmas of Desire: Teenage girls talk about sexuality. Cambridge: MA: Harvard University Press.

Tolman, D. (2003). Delemmas of Desire: Teenage girls talk about sexuality. Cambridge: MA: Harvard University Press.

Tversky, A., \& Kahneman, D. (1986). Rational Choice and the Framing of Decisions. The Journal of Business, 59(4), S251-S278.

TVNZ. (2012). Shorty ratings set a 2011 high! , from http://tvnz.co.nz/shortland-street/shorty-ratings-set-2011-high-4313046 
UNESCO. (2009). Internation Technical Guidance on Sexuality Education: An evidence-informed approach for schools, teachers and health educators. Volume 2: Topics and learning objectives. Paris: UNESCO. UNICEF. (2001). Innocenti Report Card No. 3: A League Table of Teenage Births in Rich Nations. Florence: UNICEF.

Van Empelen, P., \& Kok, G. (2006). Condom use in steady and casual sexual relationships: Planning, preparation and willingness to take risks among adolescents. Psychology and Health, 21(2), 165-181.

Wallace, L. M., Evers, K. E., Wareing, H., Dunn, O. M., Newby, K., Paiva, A., et al. (2007). Informing school sex education using the stages of change construct - Sexual behaviour and attitudes towards sexual activity and condom use of children aged 13-16 in England. Journal of Health Psychology, 12(1), 179-183.

Weaver, S., \& Herold, E. S. (2008). Casual sex and women. Journal of Psychology \& Human Sexuality, 12(3), 23-41.

Weaver, H., Smith, G., \& Kippax, S. (2005). School-based sex education policies and indicators of sexual health among young people: a comparison of the Netherlands, France, Australia and the United States. Sex Education: Sexuality, Society and Learning, 5(2), 171 188.

Wechsler, H., Dowdall, G. W., Davenport, A., \& Rimm, E. B. (1995). A Gender-Specific Measure of Binge Drinking among College Students. American Journal of Public Health, 85(7), 982-985.

Weinhardt, L. S., \& Carey, M. P. (2000). Does Alcohol Lead to Sexual Risk Behavior? Findings from Event-Level Research. Annual Review of Sex Research, 11, 125.

Weinstein, N. D. (1980). Unrealistic optimism about future life events. Journal of Personality and Social Psychology, 39(5), 806-820.

Weir, K. (2000). Sexuality Education: Who Does The Teaching? Delta, 52(2), 3-20.

Wertz, F. J., Charmaz, K., McMullen, L. M., Josselson, R., Anderson, R., \& McSpadden, E. (2011). Five Ways of Doing Qualitative Analysis. New York: The Guilford Press. 
Westwood, J., \& Mullan, B. (2006). Knowledge of secondary school pupils regarding sexual health education. Sex Education: Sexuality, Society and Learning, 6(2), 151 - 162.

Whitaker, D. J., Miller, K. S., May, D. C., \& Levin, M. L. (1999). Teenage Partners' Communication About Sexual Risk and Condom Use: The Importance Of Parent-Teenager Discussions. Family Planning Perspectives, 31(3), 117-121.

Widmer, E. D., Treas, J., \& Newcomb, R. (1998). Attitudes toward nonmarital sex in 24 countries. Journal of Sex Research, 35(4), 349-358.

Winer, R. L., Hughes, J. P., Feng, Q., O'Reilly, S., Kiviat, N. B., Holmes, K. K., et al. (2006). Condom Use and the Risk of Genital Human Papillomavirus Infection in Young Women. New England Journal of Medicine, 354(25), 2645-2654. 


\section{Appendix A: Recruitment Poster}

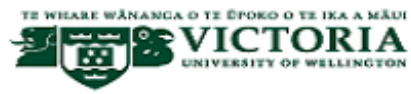

\section{Are you:}

- Female?

- Aged 18-25 years?

- Have had casual sex?

- Interested in being part of a health education research project?

I am looking for 15-20 women who are interested in talking about their experiences and how that might relate to sexual health education in schools.

This research is for a Masters thesis at Victoria University and has been reviewed and approved by the Victoria University Ethics Committee.

If you are interested contact $\mathrm{Ann}$ nette on:

Healthed2011@gmail.com

Or

Call/text and leave an email address at: 0278497622

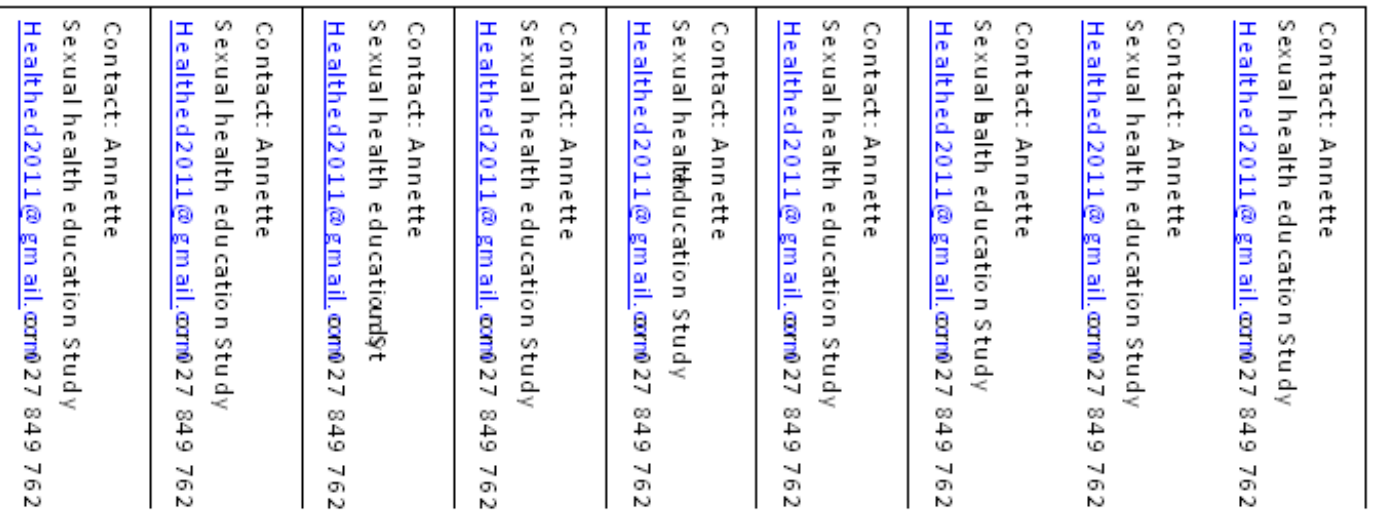




\section{Appendix B: Interview Guide}

Question 1: People under aged under 25 have the highest rates of STI's in New Zealand and one of the highest rates of unplanned pregnancy in the OCED - why do you think that is?

- Do you think things like poverty or geographical location has any effect on that?

- What about family or peers?

Question 2: What circumstances do you think increase the likelihood of someone in your age group having casual sex?

- Being out in town/drinking/clubbing?

- Being with friends?

- Having a bad day? Good day?

Question 3: Do you think people in your age group are more likely to have casual sex if they are drinking/doing drugs?

- Why do you think that is?

- How much alcohol? What kind of drugs?

- Do you think people in your age group might use alcohol as an 'excuse' or blame their actions on being drunk or high? Why/why not?

Question 4: What kind of skills do you think women or men around your age need to make good decisions around casual sex in the 'heat of the moment'?

Question 5: So where did you learn the most about sex?

- School? Friends? Internet? As it happened?

- Do you think that was the best place or situation?

- What were your experiences of health/sexuality education at school?

- What do you remember?

- What would you have liked to be different?

- More of?

- Less of

Question 6: So thinking about your own experiences has there been a time when you had casual sex but didn't use condoms?

- More than once?

- Different partners?

- How recently?

- Did your partner suggest condoms?

- Who do you think is responsible for having condoms?

- Would you be comfortable telling a partner - no sex without condoms?

- Why/why not?

- When you were making the decision to have causal sex or not, what were you thinking about or weighing up?

- Looking back, do you think this was a good decision? What do you think contributed to you making the decision you did?

- Do you feel like this experience influenced your future decision making?

- Fertility? Contraception? STIs? 
Question 7: Now that you are/have been sexually active what do think would have been helpful to know when you were 14, 15, 16, 17, 18?

- What would you suggest should be included in sexuality programmes at schools that would have been useful?

- Do you think sexual health could/should continue to be taught into the later years of high school? Up to year 13?

Question 8: Who do you think is responsible for delivering sexual education?

- School?

- Parents/guardians?

- Church?

- Friends?

- Google?

- Sexual health clinics like Family planning? Would you prefer if it was an outsider?

Question 9: How much time do you think should be spent on sexuality education in the school system?

- Days?

- Weeks? 


\title{
Appendix C: Information Sheet
}

\author{
TH WHARE WANANGA O TI DFOKO O TE IKA A MXXUI \\ † \\ NGTON
}

An examination of young women's use of condoms in casual sex situations: Implications for the school sexuality health curriculum.

\section{Information Sheet}

\begin{abstract}
You are invited to take part in a study to look at sexual behaviour and its relationship to the sexuality education curriculum.
\end{abstract}

Please read this information sheet and think about whether you would like to take part in this study. It involves you talking to an interviewer about some of your own sexual experiences and as well as your ideas for the sexuality education curriculum. These interviews will occur at a mutually agreeable time and place. If you say yes, but then change your mind before or during the interview, you can leave at any time, without having to give a reason.

What are the aims of this study?

The purpose of this research is to gain a better understanding of women's decision making around the use/non-use of condoms in casual sex situations and to get their ideas for improvements to the school sexuality curriculum.

What does this study involve?

This study involves you taking part in one interview approximately one hour long with the researcher. These interviews will be recorded with your permission.

\section{What are the benefits of taking part?}

This is a chance for you to talk about, and share your views on an issue that is really important for all women. By finding out how we might be able to improve the sexuality health curriculum in schools, rates of unintended pregnancy and STIs could be reduced. If you are interested, we will send you a summary of the findings at the end of the study.

\section{Where will the interview take place?}

The interview will be held at a mutually agreeable time and place. You are welcome to have a whanau/support person with you during the interview.

\section{Confidentiality}

- The interview is confidential and no information that could personally identify you will be used in any reports from this study.

- I would like to tape record the interview so your comments can be played back and typed up to create a written version of the interview. Your name will be removed from any transcripts and replaced with a study pseudonym or study number.

- If you wish, you will have an opportunity to review a transcript of your recording as soon as the transcription is complete.

- All information (recordings and notes) collected will be stored in a locked cabinets or a password protected computer and destroyed 5 years after the 
conclusion of the study (electronic files will be deleted and written information destroyed).

\section{What happens to the information?}

These results of this work will be used as the basis of a master's thesis at Victoria University. Sections or excerpts will also be used for conference presentations and journal articles. However, no information that can personally identify you will be used. Are there any risks to taking part?

There are no risks to your taking part in the interviews?

The researcher is used to talking about this topic. You can leave the interview at any time without giving a reason. However, should the discussion distress or upset you in any way we have provided a list of phone numbers which you may find helpful.

\section{General practitioners and family planning}

Victoria University student counselling services

Kelburn Campus - 044635310

Te Aro Campus 044635310

Karori Campus 044639537

Pipitea Campus 044637474

Massey University student counselling services - (04) 801-2542

Healthline - 0800611116

Youthline - 0800376633

Depression Helpline - 0800111757

For information on sexual or reproductive health visit www.familyplanning.org.nz

\section{Where can I get more information about the study?}

You can get more information about the study by contacting Annette:

Phone: 0278497622

Email: annettecooper00@gmail.com

Or my supervisor: Dr. Barrie Gordon

Phone: 044639770

Email: Barrie.Gordon@vuw.ac.nz 


\title{
Appendix D: Consent Form
}

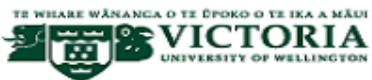

\begin{abstract}
An examination of young women's use of condoms in casual sex situations: Implications for the school sexuality health curriculum
\end{abstract}

\section{Consent form}

Interview num ber:

$P$ lease read the following sentences and tick ' $Y e s$ ' or ' $N o$ ' alongside each section if you agree to take part in this study.

1. I have read and understand the information I have been given. I have had the chance to talk about this study and am happy with the answers given.

2. I understand that taking part in this study is my choice, and that I can le ave the interview at any time.

3. I understand that taking part in this study is confidential (private) and that no information that could identify $m e$ will be used in any reports on this study.

4. I have had time to think about whether to take part and I know who to contact if I have any questions about the study.

\begin{tabular}{|l|l}
$\square$ Yes & $\square$ No \\
$\square$ Yes & $\square$ No
\end{tabular}

. I agree to the interview being tape-recorded so the researcher can listen to the interview afterwards, and type it up (transcribe it) for analys is .

6. I would like a copy of the transcript ( $w$ ritten version of the interview) sent to $\mathrm{me}$ at the end of the study.

If yes, please provide a confidential email or postal address below

7. I would like to be sent a sum mary of the study findings

If yes, please provide a confidential email or postal address below

$m$ ail:

Post:

Post.

Your signature:

। (full name) agree to take part in this study

Signature: Date: 